\title{
The NLRP3-Mediated Neuroinflammatory Responses to CdTe Quantum Dots and the Protection of ZnS Shell
}

This article was published in the following Dove Press journal: International Journal of Nanomedicine

\author{
Tianshu Wu (D) \\ Xue Liang' \\ Keyu $\mathrm{He} \mathbb{D}^{2}$ \\ Xi Liu' \\ Yimeng Li' \\ Yutong Wang' \\ Lu Kong (D) \\ Meng Tang'
}

'Key Laboratory of Environmental Medicine and Engineering, Ministry of Education, School of Public Health, Southeast University, Nanjing 210009, People's Republic of China; ${ }^{2}$ Blood Transfusion Department, Zhongda Hospital, Southeast University, Nanjing 210009, People's Republic of China
Correspondence: Tianshu Wu Email ninatswu@I26.com
Introduction: Since CdTe quantum dots (QDs) are still widely considered as advanced fluorescent probes because of their far superior optical performance and fluorescence efficiency over non-cadmium QDs, it is important to find ways to control their toxicity.

Methods: In this study, the adverse effects of two cadmium-containing QDs, ie, CdTe QDs and CdTe@ZnS QDs, on the nervous system of nematode C. elegans, the hippocampus of mice, and cultured microglia were measured in order to evaluate the neuroinflammation caused by cadmium-containing QDs and the potential mechanisms.

Results: Firstly, we observed that cadmium-containing QD exposure-induced immune responses and neurobehavioral deficit in nematode $C$. elegans. In the mice treated with QDs, neuroinflammatory responses to QDs in the hippocampus, including microglial activation and IL-1ß release, occurred as well. When investigating the mechanisms of cadmium-containing QDs causing IL-1ß-mediated inflammation, the findings suggested that cadmium-containing QDs activated the NLRP3 inflammasome by causing excessive ROS generation, and resulted in IL- $1 \beta$ release.

Discussion: Even though the milder immune responses and neurotoxicity of CdTe@ZnS QDs compared with CdTe QDs indicated the protective role of $\mathrm{ZnS}$ coating, the inhibitions of NLRP3 expression and ROS production completely reduced the IL-1ß-mediated inflammation. This provided valuable information that inhibiting target molecules is an effective and efficient way to alleviate the toxicity of cadmium-containing QDs, so it is important to evaluate QDs through a mechanism-based risk assessment.

Keywords: quantum dot, Caenorhabditis elegans, hippocampus, BV2 cells, interleukin-1ß, NLRP3 inflammasome

\section{Introduction}

Quantum dots (QDs) can be used as fluorescence nanoparticles for applications in targeted drug delivery and biomedical imagery due to their superior optical properties. ${ }^{1,2}$ Among various types of QDs, cadmium-containing QDs are still optimal in some biomedical cases with requirements of high detective sensitivity because their fluorescence quantum yield (FLQY) is above $70 \%$, which is far superior optical performance over non-cadmium QDs. ${ }^{3}$ Meanwhile, along with the rapidly growing development and application of cadmium-containing QDs, the chance of them becoming an environmental concern is increasing. As is widely acknowledged, a major issue for QDs containing cadmium is toxicity, so it is a huge challenge to assure their safety in the population and the environment through 
conducting mechanism-based risk assessments of cadmium-containing QDs or optimizing QD synthesis to alleviate their toxicity. ${ }^{4,5}$

There are studies reporting that cadmium-containing QDs can be used to diagnose and treat central nervous system (CNS) disorders, but they could be dangerous to the normal CNS because of their tiny size. ${ }^{6}$ Therefore, it is important to assess the adverse effects of cadmiumcontaining QDs in the CNS and their potential mechanisms. Our previous work suggested bare-core cadmium telluride (CdTe) QDs exposure-induced inflammatory cell infiltration in the hippocampus of rats, but the neuroinflammatory responses to CdTe QDs in vivo and targeted molecules are underrepresented. $^{7,8}$

Most researchers agree that the release of toxic cadmium ions is how cadmium-containing QDs, like CdTe QDs, cause toxicity. Some studies have reported the protective role of the zinc sulfide $(\mathrm{ZnS})$ shell encasing the CdTe core through insulating against the release of cadmium in living organisms. ${ }^{9,10}$ Moreover, CdTe QDs with ZnS coating (CdTe@ZnS core@shell QDs) were considered to have improved function as a fluorescent probe than core-bare CdTe QDs in biomedical application, due to their higher quantum yield, dispensability, and biocompatibility, ${ }^{11}$ but the protection of the $\mathrm{ZnS}$ coating from the toxicity of CdTe QDs is far less documented.

Although our research group has shown the roles of sizes and surface coatings influencing the neuroinflammatory reactions to $\mathrm{CdTe}$ QDs in neuronal cells, ${ }^{12,13}$ the neuroinflammation-promoting effects of CdTe QDs in in vivo biological models are still not clear. In this study, two animal models, ie, Caenorhabditis elegans and Institute of Cancer Research (ICR) mice, were used. Owning to the simple but sophisticated informed nervous system of $C$. elegans, these nematodes have been shown to be reliable in numerous neurotoxicological studies evaluating various chemicals. ${ }^{14}$ The highly complex immunity of vertebrates has evolved from the relatively simple immune system of $C$. elegans, so they are also experimentally advantageous to study the host defense or inflammatory functions by testing relevant pathways, such as insulin (Daf-2/Daf-16) signaling and the p38 mitogen-activated protein kinase (MAPK) pathway. ${ }^{15,16}$

In addition, this study investigates the neuroinflammatory responses to QDs in the hippocampus of mice and the underlying mechanisms, as the hippocampus has been found to be the main domain in the brain for the accumulation of CdTe QDs. ${ }^{7,13}$ The BV2 microglial cell line is then used to confirm the molecular targets to cadmiumcontaining QDs in the mediation of neuroinflammation. The detailed comparative information obtained throughout this study about the toxicity of CdTe QDs and CdTe@ZnS QDs will provide valuable information for the bio-safe application of cadmium-containing QDs in the near future.

\section{Materials and Methods}

\section{Preparation and Characterization of QDs}

In this study, MPA-modified CdTe QDs and core-shell CdTe@ZnS QDs were both water-soluble and prepared as described previously with some improved modifications. ${ }^{17,18}$ The physicochemical properties of CdTe QDs and CdTe@ZnS QDs were evaluated as the method described in a previous study. ${ }^{12}$ All characteristic data of QDs are presented in Table S1 and Figure S1.

\section{Endotoxin Testing}

The Gram-negative bacterial endotoxin in solutions of $5 \mathrm{nM}$ CdTe QD and CdTe@ZnS QD was detected by using an end-point Limulus Amebocyte Lysate (LAL) assay based on the protocol described in a previous study. ${ }^{19}$ All treatments were independently performed three times.

\section{Cell Culture and Treatment}

The BV2 cell line was purchased from the Shanghai Cell Research Center (Shanghai, China) and maintained using the method described in a previous study. ${ }^{19}$ The exposure concentrations of CdTe QDs and CdTe@ZnS QDs were $1.25 \mathrm{nM}$ and $5 \mathrm{nM}$, and the exposure time was $12 \mathrm{~h}$, based on results from previous studies. ${ }^{13}$

\section{MTT Assay}

The BV2 cells were incubated in the 96-well plate with a density of $1 \times 10^{4}$ cells/well in a total volume of $100 \mu \mathrm{L}$, and allowed to attach and grow for $24 \mathrm{~h}$ at $37^{\circ} \mathrm{C}$. The supernatant in each well was then replaced with serum-free maintenance medium containing $1.25 \mathrm{nM}$ and $5 \mathrm{nM}$ CdTe QDs and CdTe@ZnS QDs. After exposure to QDs for 12 h, $20 \mu \mathrm{L}$ of MTT (5 mg/mL; Sigma-Aldrich, Shanghai, China) was added into each well and incubated for $4 \mathrm{~h}$ at $37^{\circ} \mathrm{C}$. The supernatant was then replaced with $150 \mu \mathrm{L} /$ well dimethyl sulfoxide (Sigma-Aldrich). The plate was shaken for $15 \mathrm{~min}$ to dissolve the dark blue formazan products and measured using the Epoch multi-volume spectrophotometer system (BioTek, Winooski, VT, USA) at a wavelength of $570 \mathrm{~nm}$ 
to get the spectrophotometric data. The assay was performed independently in triplicate.

\section{Detection of Pro-Inflammatory Cytokine Production}

Relevant ELISA Commercial Reagent Kits (Yi Fei Xue Biotechnology, Nanjing, China) were used to detect the levels of IL- $1 ß$ and TNF- $\alpha$ in serum, hippocampus, and cell culture supernatants based on the manufacturer's protocol. All treatments were independently performed three times.

\section{Detection of Intracellular Reactive Oxygen Species (ROS) Generation in Cells}

The oxidation-sensitive fluorescence probe $2^{\prime}, 7^{\prime}$ dichlorofluorescein diacetate (DCFH-DA) (Beyotime Biotechnology, Shanghai, China) was used to measure the intracellular ROS according to the manufacturer's instruction and methods in a previous study. ${ }^{19}$ All treatments were independently performed three times.

\section{RNA Interference (RNAi) Assay}

The RNA oligonucleotides prepared by Genechem (Shanghai, China) were transferred into BV2 cells by using the lentivirus infection reagent (Genechem) based on the manufacturer's protocol. The siRNA sequences of NLRP3 were 5'-UUUUCCCAGAGGUCUCGCCTT-3' and 5'-GGCGAGACCUCUGGGAAAATT-3'.

\section{Nematodes and Treatment}

The wild-type N2 C. elegans strain and the Escherichia coli OP50 strain were acquired from the Caenorhabditis Genetics Center (CGC) (University of Minnesota, MN, USA). The nematodes were cultured and manipulated using standard methods. ${ }^{20}$ The final concentrations of CdTe QDs and CdTe@ZnS QDs were $0.01 \mu \mathrm{M}$ and $1 \mu \mathrm{M}$ on the surface of each well. Synchronized L4-stage and L1-stage nematodes were exposed to cadmium-containing QDs for 24 and $72 \mathrm{~h}$, respectively.

\section{Uptake of QDs by Nematodes}

The concentration of $\mathrm{Cd}$ in nematodes treated with QDs was measured by using a graphite furnace atomic absorption spectroscopy (5100ZL Zeeman Furnace Module, Perkin-Elmer, Norwalk, CT) based on a similar protocol described in a previous study. ${ }^{19}$ The fluorescent images were obtained using a fluorescence microscope to show the uptake and distribution of QDs by nematodes. All treatments were independently performed three times.

\section{Lifespan Assay}

The survival analyses of $C$. elegans were carried out at $20^{\circ}$ $\mathrm{C}$ according to the protocol from the research of Zhuang et al. ${ }^{21}$ In each treatment, sixty nematodes were examined, and three replicates were independently performed.

\section{Locomotion Behavior Assay}

The forward locomotion tracks were observed as a nematode that was picked on an NGM agar plate with food moving freely for $1 \mathrm{~min}^{22}$ The body bend and head thrashes were measured as described in a previous study. ${ }^{23}$ Thirty nematodes were examined in each treatment using a stereomicroscope (Olympus, SZ61) and all treatments were independently performed three times.

\section{Measurement of ROS Generation in Nematodes}

The oxidation-sensitive fluorescence probe DCFH-DA (Beyotime Biotechnology) was also used to detect the ROS generation in nematode $C$. elegans but using a fluorescence microscope. All treatments were independently performed three times.

\section{Mice and Treatment}

Thirty-five male ICR mice (7 mice for each group) used in this study were aged 6 weeks and weighed around 20 g. They were purchased from the Shanghai Super B\&K laboratory animal Corp. Ltd (Shanghai, China), and housed as described previously. ${ }^{19}$ All animal procedures were performed in strict accordance with the Guidelines for Care and Use of Laboratory Animals of Southeast University and experiments were approved by the Animal Experimental Ethics Committee of Southeast University (Nanjing, China).

The administration exposure was intravenous injection through tail veins, and the administration doses were 0.25 and $2.5 \mathrm{mM} \times 0.1 \mathrm{~mL} / 20 \mathrm{~g}$ body weight (BW) of CdTe QDs and CdTe@ZnS QDs and normal saline (the control). The brains and the dissected hippocampi were taken after the injection for $3 \mathrm{~h}, 24 \mathrm{~h}$, and 28 days.

\section{Blood Routine and Biochemical Test}

The routine blood indicators and biochemical indicators in serum were measured as the protocol in the previous study. ${ }^{19}$ 


\section{Pathological Examination}

The organ coefficient of the brain was calculated by dividing weight by the weight of the brain of an individual mouse. The histopathological examination of the brain was performed using a standard laboratory procedure.

\section{Immunofluorescence}

The ice slices of hippocampi were performed using a standard laboratory. ${ }^{19}$ The reagents of primary antibodies, ie, anti-PECAM, anti-Iba-1, anti-CD16, anti-CD206, and anti-GFAP, and secondary antibodies, ie, Alexa Fluor ${ }^{\circledR} 488$ and $\mathrm{Cy} 3$, and conjugated anti-mouse $\operatorname{IgG}$, were all purchased from Cell Signaling Technology, Inc.

\section{Quantitative Real-Time}

\section{Reverse-Transcription Polymerase Chain Reaction (qRT-PCR) Analysis}

Total RNA of $C$. elegans and hippocampus was extracted to do the qRT-PCR analysis, which was carried out following the protocol described in a previous study. ${ }^{13}$ The qRTPCR primers that were designed by using software Primer Premier based on National Center for Biotechnology Information (NCBI) are shown in Table S2. All treatments were independently performed three times.

\section{Western Blotting}

Total protein of BV2 cells and hippocampus, as well as the cytoplasm and nuclear protein of BV2 cells, were extracted to perform Western blotting analysis, which was carried out following the protocol described in a previous study. ${ }^{13}$ The reagents of primary antibodies, ieanti-NLRP3, anti-IL-1ß, and anti-GAPDH were purchased from Cell Signaling Technology, Inc. All treatments were independently performed three times.

\section{Transcriptome Analysis}

The treatment of male Wistar rats and the detailed protocol of transcriptome analysis were described in the previous study. ${ }^{8}$

\section{Data Analysis}

All quantitative data were displayed as the mean \pm standard deviation (SD). The SPSS Statistics 19.0 Software was used to perform statistical analysis. The statistical significance between control and exposed groups was detected by one-way analysis of variance (ANOVA) following with Tukey LSD (least significant difference) post hoc test. Statistical significance was considered as probability $<0.05$ and $<0.01$.

\section{Results}

\section{Cadmium-Containing QD Exposure Induced the Immune Responses in Nematode $C$. elegans}

The uptake and distribution of CdTe QDs and CdTe@ZnS QDs in an intact living nematode were visualized by using fluorescence microscopy due to the bright fluorescence of cadmium-containing QDs and the transparent body of C. elegans. The representative images showed that the CdTe QDs and CdTe@ZnS QDs, showing red fluorescence, both spread over the whole body. The digestive system of worms was where the QDs were mainly distributed, which might be attributed to the exposure route through the digestive tract (Figure S2A). The level of cadmium-containing QDs in worms, by measuring the concentration of $\mathrm{Cd}$, remarkably increased along with the increasing administration concentration, but slightly increased when the exposure time reached $72 \mathrm{~h}$ (Figure S2B). This might be attributed to the elimination of QDs following with the exposure time. ${ }^{24}$

The lifespan of $C$. elegans is a sensitive toxic endpoint associated with the immune responses to foreign chemicals. ${ }^{25,26}$ It is obvious that the survival rates in CdTe QDs and CdTe@ZnS QDs-treated nematodes were different from the control, especially after day 15 , and the nematodes treated with $1 \mu \mathrm{M}$ CdTe QDs had obviously lower survival rates than nematodes exposed to CdTe@ZnS QDs at the same exposure concentration (Figure 1A). The falling range of lifespan caused by CdTe QDs was obviously larger than that caused by CdTe@ZnS QDs, which indicated CdTe QD exposure might induce a more severe immune reaction than CdTe@ZnS QDs in C. elegans.

The expression levels of immune genes lys-1, spp-1, and dod-6 increased to some extent in nematodes treated with CdTe QDs for $24 \mathrm{~h}$ or $72 \mathrm{~h}$, while only $1 \mu \mathrm{M}$ CdTe@ZnS QD exposure caused the expression of lys-1 to increase over twofold compared to the control when the exposure time reached $72 \mathrm{~h}$ (Figure 1B-D). Meanwhile, the expressions of genes pmk-1, daf-2, and daf-16, which are key molecules in signal pathways regulating immunity of nematodes, were also upregulated in nematodes after CdTe QD treatment for $24 \mathrm{~h}$ or $72 \mathrm{~h}$, while only $1 \mu \mathrm{M}$ CdTe@ZnS QD exposure for $24 \mathrm{~h}$ caused the expression 
A

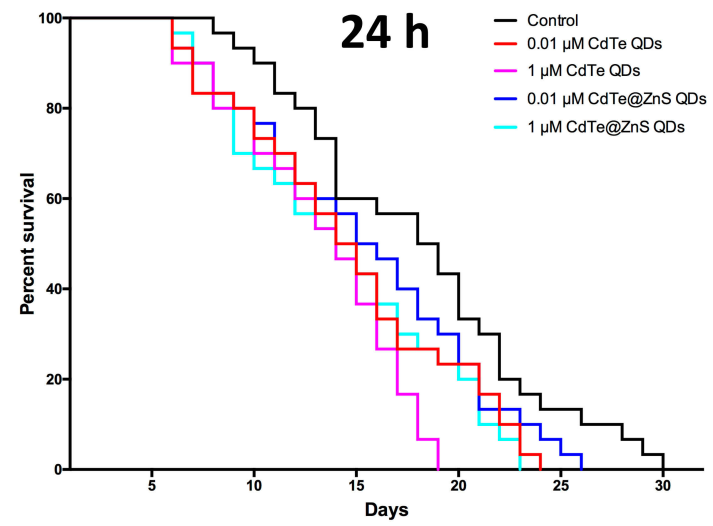

B

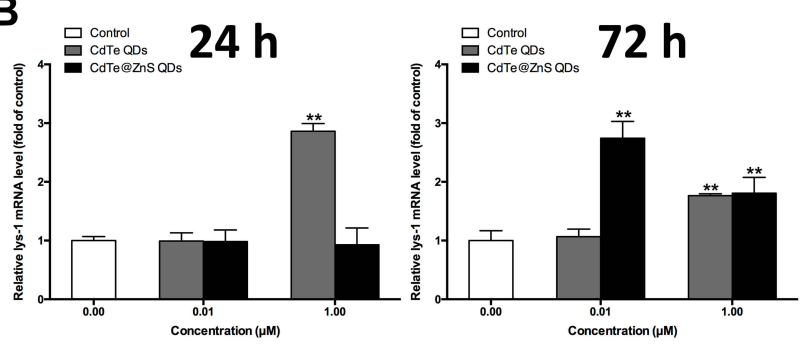

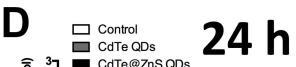
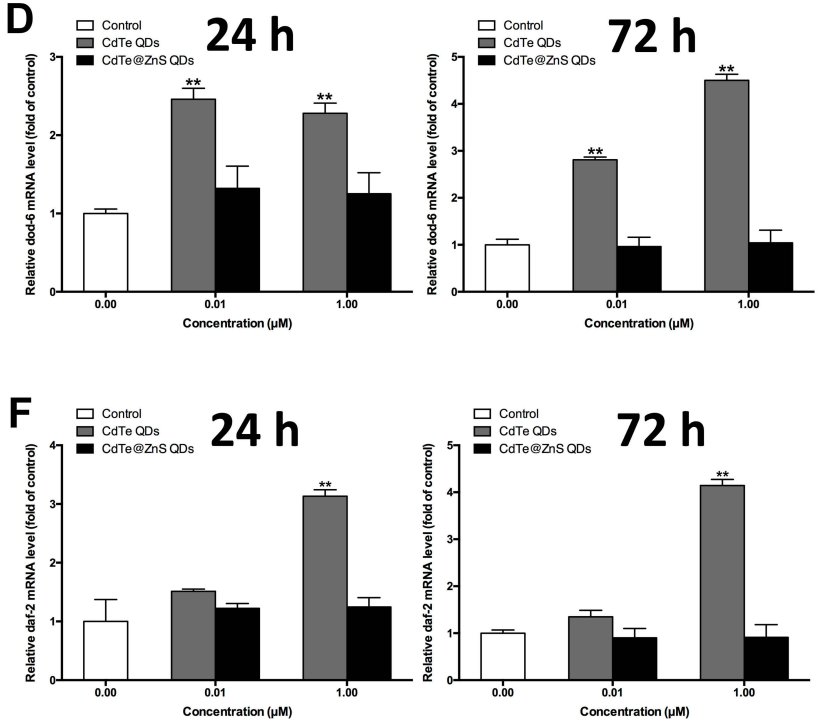

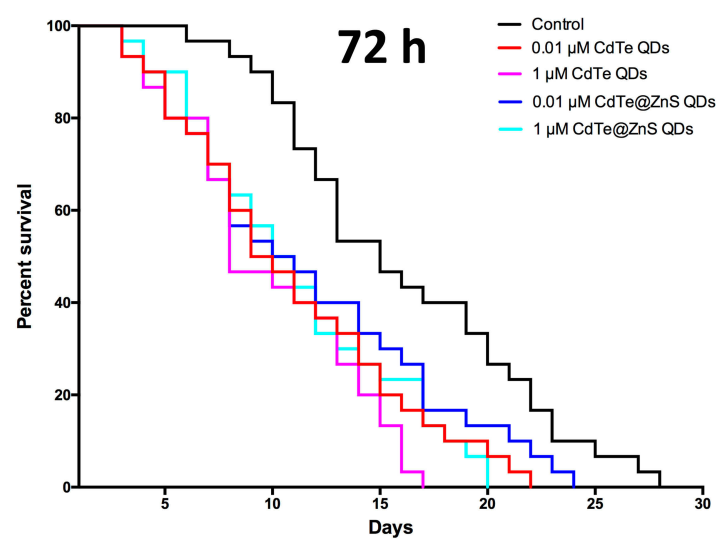

C
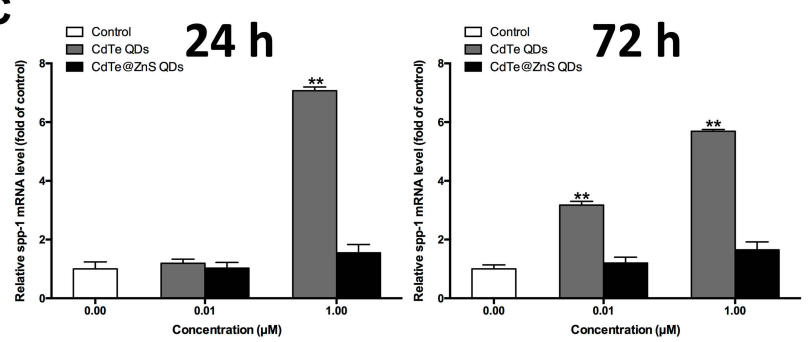

E
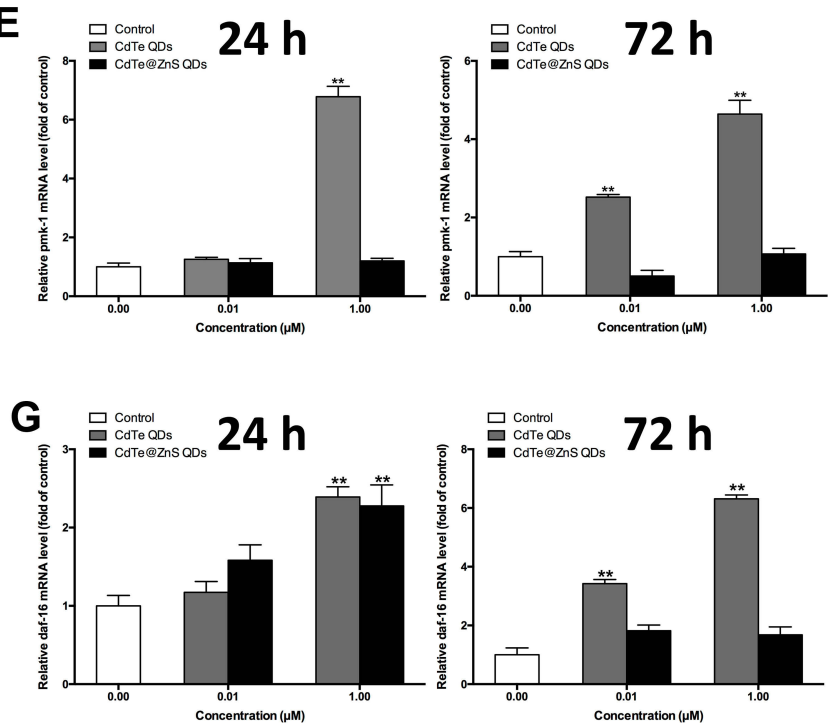

Figure I The toxic effects of cadmium-containing QDs in the immunity system of C. elegans. (A) The effects of $0.01 \mu M$ and I $\mu M$ CdTe QD and CdTe@ZnS QD treatment for 24 $\mathrm{h}$ and $72 \mathrm{~h}$ in the lifespan of $C$. elegans; and the effects of $0.01 \mu \mathrm{M}$ and I $\mu \mathrm{M}$ CdTe QD and CdTe@ZnS QD treatment for $24 \mathrm{~h}$ and $72 \mathrm{~h}$ in the expression of lys-I (B), spp-I (C), dod-6 (D), pmk-I (E), daf-2 (F) and daf-I6 (G) mRNA in C. elegans measured by qRT-PCR analysis. Data are presented as the mean \pm SE of experiments performed independently three times. The one-way ANOVA following with the Tukey LSD post hoc test was used to determine statistically significant $(* * P<0.0 \mathrm{I}$ vs the control).

of daf-16 to be upregulated over twofold when compared to the control (Figure 1E-G).

\section{The Nervous System of Nematode}

\section{C. elegans Was Damaged by}

\section{Cadmium-Containing QD Exposure}

The locomotion alteration of nematodes has been reported in several studies to evaluate the neurotoxicity of nanomaterials. ${ }^{27,28}$ Firstly, we observed the forward locomotion trackers of $C$. elegans and found that nematodes treated with $1 \mu \mathrm{M}$ CdTe QDs for $72 \mathrm{~h}$ became a little disjointed, while those in CdTe@ZnS QD-treated groups exhibited no difference to the control (Figure 2A). Furthermore, $1 \mu \mathrm{M}$ CdTe QD exposure for $72 \mathrm{~h}$ significantly damaged the body bends and head thrashes in nematodes, two quantitative 
behavior indicators assessing neurotoxicity, when compared to the control, while the head thrashes reduced only in nematodes treated with $1 \mu \mathrm{M}$ CdTe QDs and CdTe@ZnS QDs for 24 h (Figure 2B and $\mathrm{C})$.

\section{Cadmium-Containing QD Exposure}

Caused Systematic and Brain

\section{Inflammation in Mice}

The results suggested that there was no difference in the growth rate of the weight of mice at the statistical level

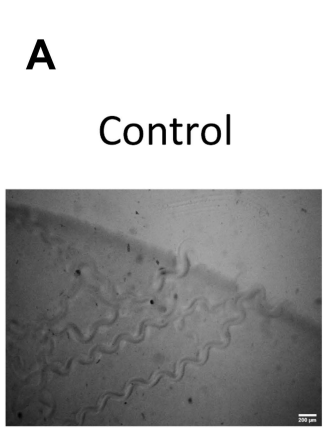

$24 \mathrm{~h}$

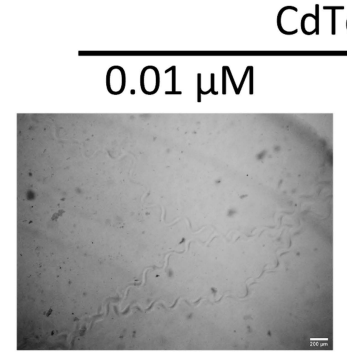

CdTe QDs
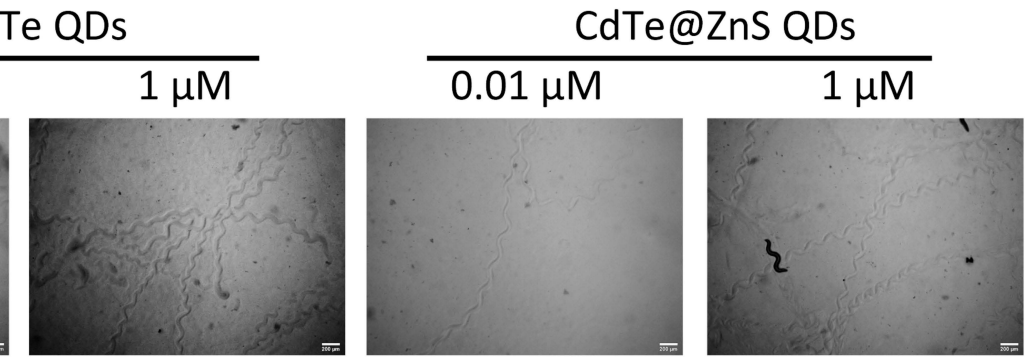

$72 \mathrm{~h}$

Control

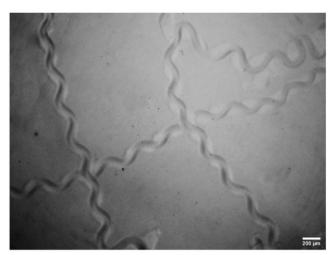

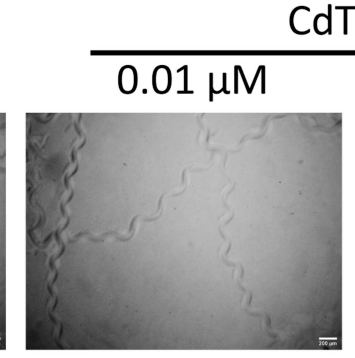

CdTe QDs
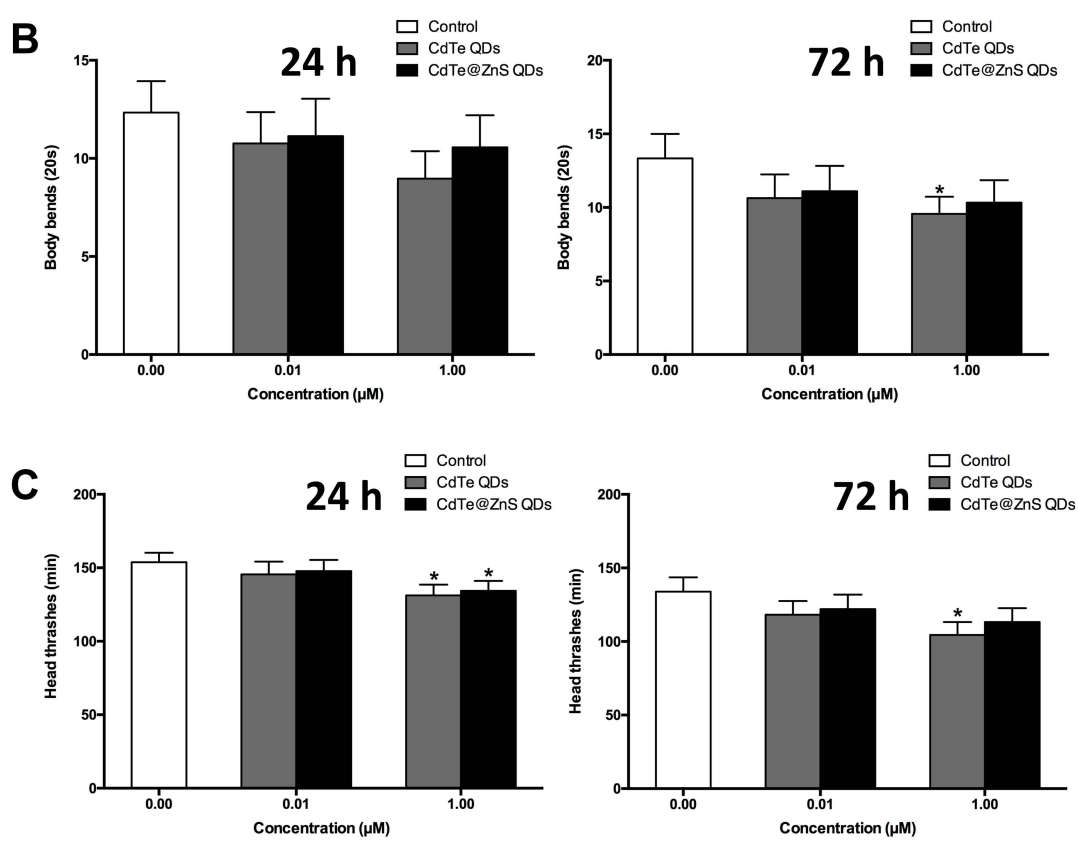

Figure 2 The toxic effects of cadmium-containing QDs in the nervous system of $C$. elegans. (A) Representative images showing the effects of $0.01 \mu M$ and I $\mu M C d T e$ QD and CdTe@ZnS QD treatment for $24 \mathrm{~h}$ and $72 \mathrm{~h}$ in the forward locomotion tracker of $C$. elegans. Magnification $(\times 100)$. The effects of $0.0 \mathrm{I} \mu \mathrm{M}$ and I $\mu \mathrm{M}$ CdTe QD and $\mathrm{CdTe} @ Z n S$ QD treatment for $24 \mathrm{~h}$ and $72 \mathrm{~h}$ in the quantity of body bends $(\mathbf{B})$ and the quantity of head thrashes $(\mathbf{C})$ in $C$. elegans. Data are presented as the mean $\pm \mathrm{SE}$ of experiments performed independently three times. The one-way ANOVA following with Tukey LSD post hoc test was used to determine statistically significant $(* P<0.05$ vs the control). 
between cadmium-containing QD groups and the control (Figure S3A). However, some slight changes were observed in routine blood indexes in mice treated with QDs, including white blood count, hemoglobin, neutrophil cell, and monocyte (Table S3), and plasma biochemical indexes indicated some hepatic and renal functions, including glutamic oxaloacetic transaminase and alkaline phosphatase (Table S4). Importantly, the results showed that $2.5 \mathrm{mM}$ cadmium-containing QD exposure significantly increased the levels of two pro-inflammatory cytokines, ie, IL-1ß and TNF- $\alpha$, in the serum of mice comparing to the control, and the increased levels in CdTe QD group were higher than those in CdTe@ZnS QD group (Figure S3B).

The organ coefficient was firstly used to assess the neurotoxicity of QDs, and only the organ coefficient in 2.5 mMCdTe@ZnS QDs-treated group reduced significantly in comparison to the control (Figure 3A). Even though there were no severe pathological lesions in the hippocampus of mice exposed to QDs, neutrophil infiltration was observed in the hippocampus of mice treated with $2.5 \mathrm{nM}$ CdTe QDs for 28 days (Figure 3B). The fluorescence of adhesion molecule platelet endothelial cell adhesion molecule-1 (PECAM-1/CD31) in the hippocampus of mice exposed to CdTe QDs and CdTe@ZnS QDs for $24 \mathrm{~h}$ and 28 days, especially $2.5 \mathrm{mM}$ CdTe QDs, was clearly brighter than the control, which indicated obvious increases in the expression of PECAM-1/CD31 (Figure 3C).

\section{Cadmium-Containing QD Exposure- Induced Microglial Activation Followed by Mainly IL-I B-Mediated Inflammation in the Hippocampus}

It has been noted that the co-localization of Iba1 with CD16 or CD206 could be used to identify activated microglia in phenotypes of M1 (pro-inflammatory) or M2 (antiinflammatory and repair-like), respectively. ${ }^{29}$ The brighter fluorescence than the control indicated that cadmiumcontaining QD exposure caused microglial activation into both M1 phenotype polarization and M2 phenotype polarization in the hippocampus (Figure 4A and B)

Additionally, the level of IL- $1 \beta$ significantly increased in the hippocampus of mice treated with $2.5 \mathrm{mM}$ CdTe QDs for $24 \mathrm{~h}$ and 28 days, and $2.5 \mathrm{mM} \mathrm{CdTe@ZnS} \mathrm{QDs}$ for 28 days when compared to the control, which indicated the inflammatory responses to cadmium-containing QDs in the hippocampus, but the levels of TNF- $\alpha$ showed no changes (Figure 4C). The astrocyte activation was observed in the hippocampus of mice exposed to CdTe QDs and CdTe@ZnS QDs for 28 days, especially $2.5 \mathrm{mM}$ CdTe QDs, which was evidenced by the brighter fluorescence of GFAP than the control (Figure S4).

In order to determine the mechanisms of QDs causing microglial activation following inflammatory cytokine release, the endotoxin levels of QD preparations were firstly detected due to the confirmed pro-inflammatory ability of endotoxin. The endotoxin levels of CdTe QDs and CdTe@ZnS QD preparations were near the detection limit, ie $0.01 \mathrm{EU} / \mathrm{mL}$ in this study, and were considered as endotoxin-free (Table S5). Therefore, the endotoxin in QD solution would not be a reason causing inflammation in BV2 cells.

\section{The Involvement of NLRP3 Inflammasome Activation in the IL-IB Secretion Caused by Cadmium- Containing QDs}

The transcriptome analysis showed remarkable upregulation in the expressions of differentially expressed genes (DEGs) encoding main components of NLRP3 inflammasome (Figure S5A), and significantly enriched the NODlike receptor (NLR) signaling pathway in the hippocampus exposed to CdTe QDs when compared to the control (Figure S5B). Furthermore, we found that the expressions of caspase-1 relevant to NLRP3 activation were significantly upregulated, but the expressions of caspase proteins relevant to apoptosis, such as caspase-3, caspase-6, and caspase-9, did not change in the hippocampus after CdTe QD treatment (Figure S5C).

The expressions of genes associated with the NLRP3 inflammasome all statistically significantly increased than the control in the hippocampus of mice exposed to $2.5 \mathrm{mM}$ CdTe QDs and CdTe@ZnS QDs for 24 h, but did not change for 28 days (Figure 5A). Meanwhile, we also observed significant increases in the expression levels of protein NLRP3, pro-IL-1ß, and IL-1ß in the hippocampus of mice exposed to cadmium-containing QDs for 28 days when compared with the control (Figure 5B). The caspase-1 activity also enhanced in the hippocampus after CdTe QD treatment at the high dose for $24 \mathrm{~h}$ and two cadmium-containing QDs at the high dose for 28 days (Figure 5C). Generally, the increases in the protein NLRP3 expression and caspase-1 activity in the hippocampus after CdTe QD treatment were all less than those after CdTe@ZnS QD treatment. 
A

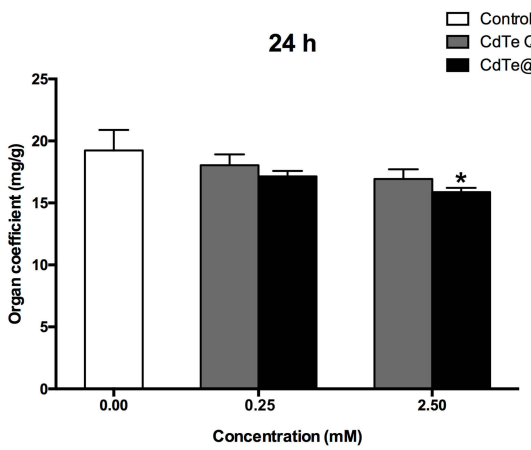

B
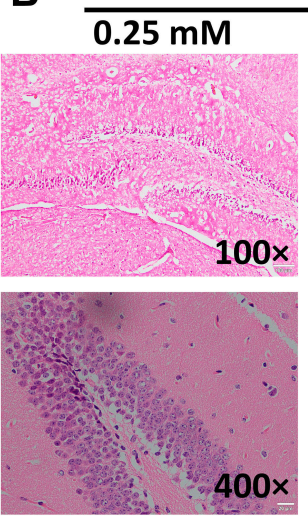

$400 x$

C
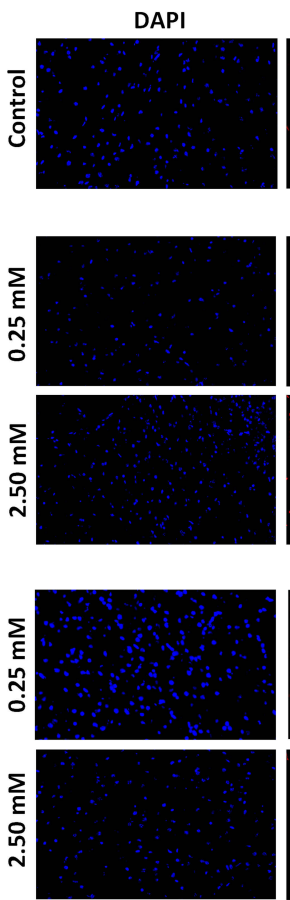

$24 \mathrm{~h}$

PECAM-1

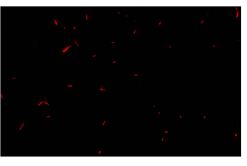

CdTe QDs
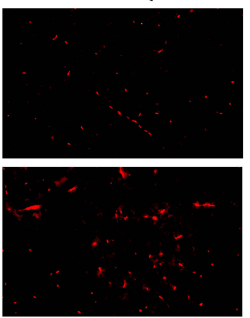

CdTe@Zns QDs
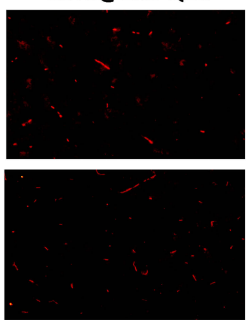

Control
$\square$ CdTe QDs CdTe@ZnS QD
28 d Control

$\square$ CdTe QDs

- CdTe@ZnS QD

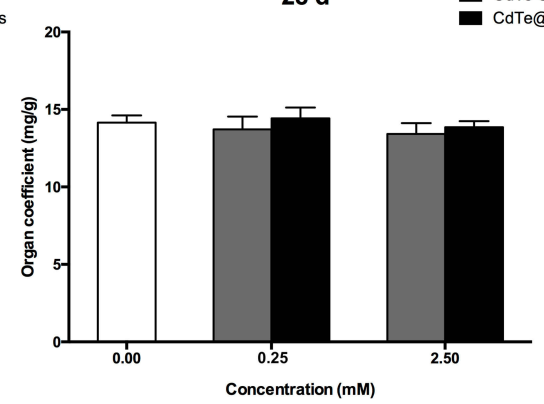

CdTe@ZnS QDs

$0.25 \mathrm{mM}$

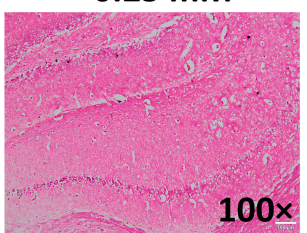

$2.50 \mathrm{mM}$

\section{Control}

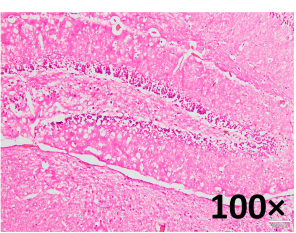

\section{8 days}

Merge
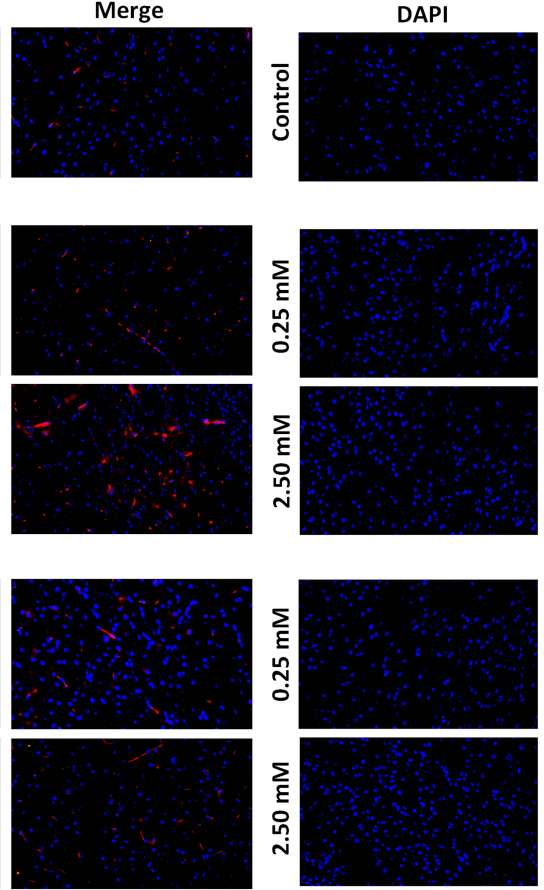

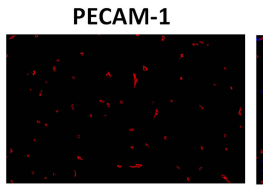

CdTe QDs

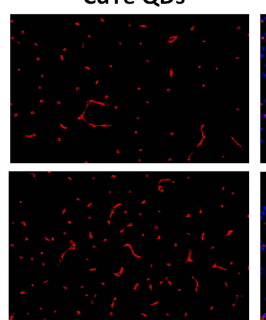

CdTe@ZnS QDs

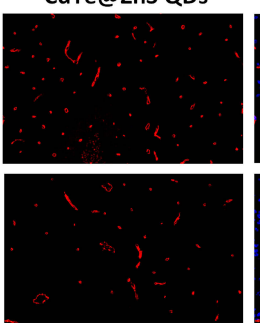

Merge
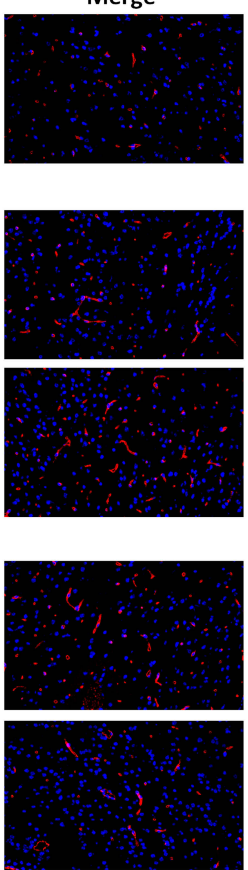

Figure 3 The toxic effects of cadmium-containing QDs in the brain of mice. (A) The effect of $0.25 \mathrm{mM} \times 0.1 \mathrm{~mL} / 20 \mathrm{~g}$ BW and $2.5 \mathrm{mM} \times 0.1 \mathrm{~mL} / 20 \mathrm{~g}$ BW CdTe QD and CdTe@ZnS QD treatment for $24 \mathrm{~h}$ and 28 days on the brain weight. Data are presented as the mean \pm SE of experiments performed independently three times. The one-way ANOVA following with Tukey LSD post hoc test was used to determine statistically significant ( $* P<0.05$ vs the control). (B) Representative histological images presented the hippocampus of mice injected with $0.25 \mathrm{mM} \times 0.1 \mathrm{~mL} / 20 \mathrm{~g}$ BW and $2.5 \mathrm{mM} \times 0.1 \mathrm{~mL} / 20 \mathrm{~g}$ BW CdTe QDs and CdTe@ZnS QDs for 28 days. The arrows indicated neutrophils. Magnification ( $\times 100$ and $\times 400)$. (C) Representative immunofluorescence images presented the expression of PECAM-I (CD3I) in the hippocampus of mice injected with $0.25 \mathrm{mM} \times 0.1 \mathrm{~mL} / 20 \mathrm{~g} B W$ and $2.5 \mathrm{mM} \times 0.1 \mathrm{~mL}$ $20 \mathrm{~g}$ BW CdTe QDs and CdTe@ZnS QDs for $24 \mathrm{~h}$ and 28 days. The PECAM-I showed red by using primary antibodies with cy3-linked secondary antibodies, and the nucleus showed blue by using DAPI. Magnification $(\times 200)$. 
A
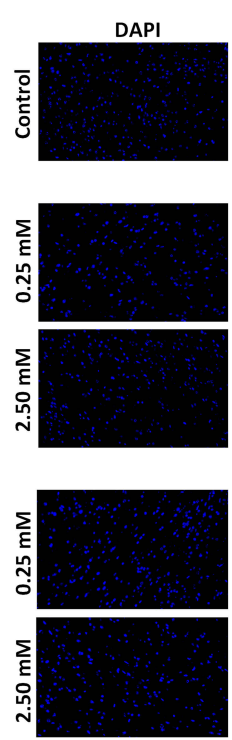

B
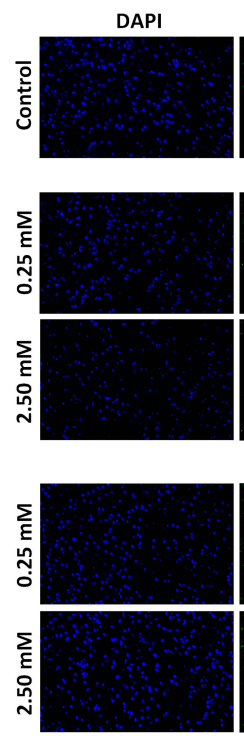

C

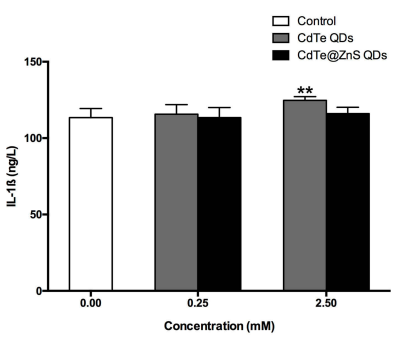

$24 \mathrm{~h}$

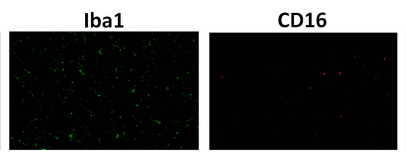

CdTe QDs

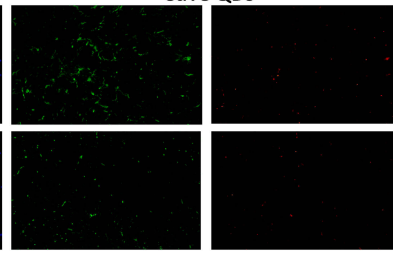

CdTe@ZnS QDs

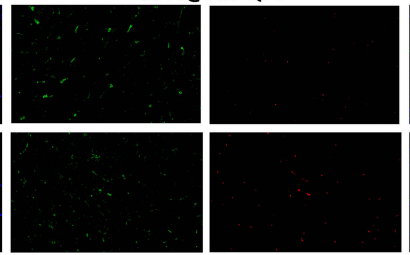

$24 \mathrm{~h}$

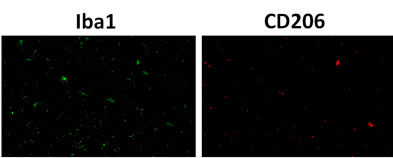

CdTe QDs

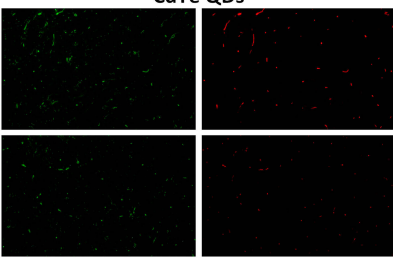

CdTe@Zns QDs

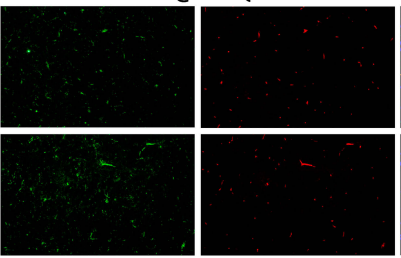

$24 \mathrm{~h}$

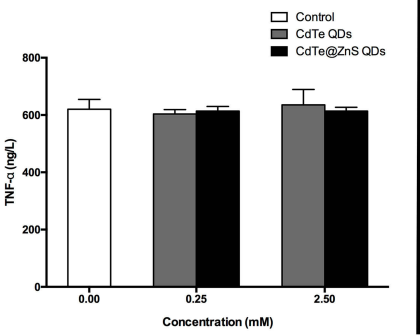

Merge
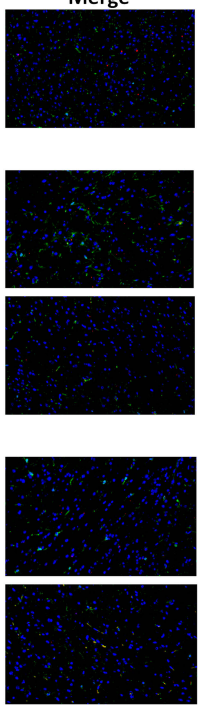

Merge
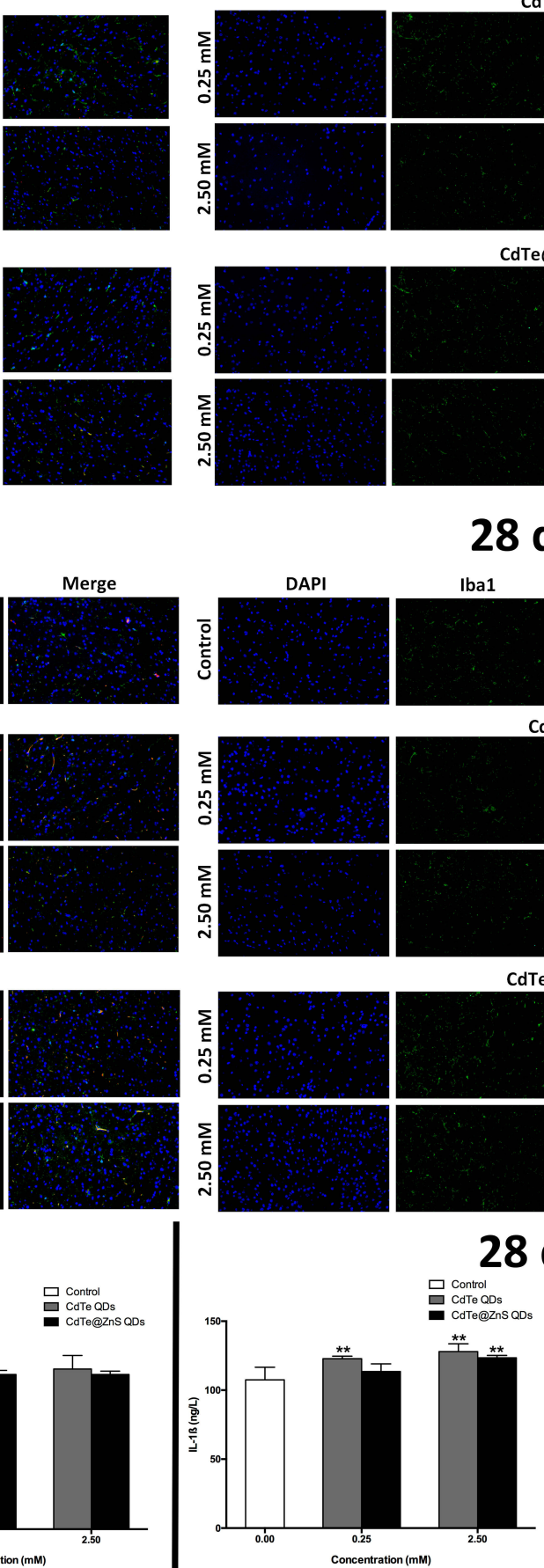

Iba1
28 days

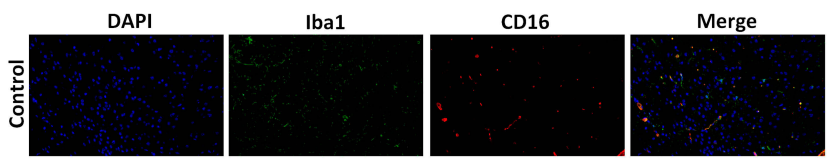

CdTe QDs

CdTe@ZnS QDs

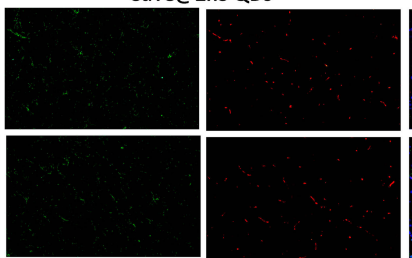

28 days

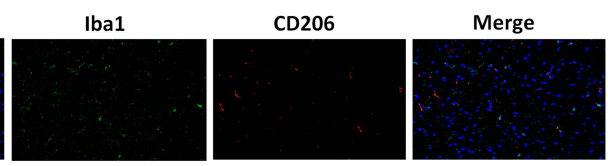

Merge

CdTe QDs

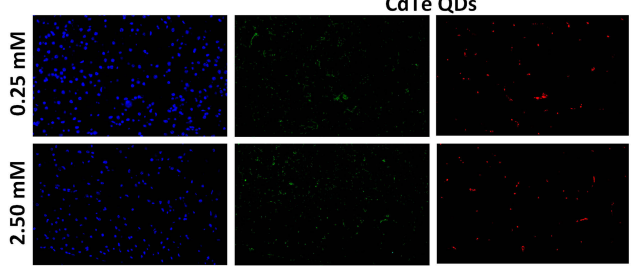

CdTe@ZnS QDs

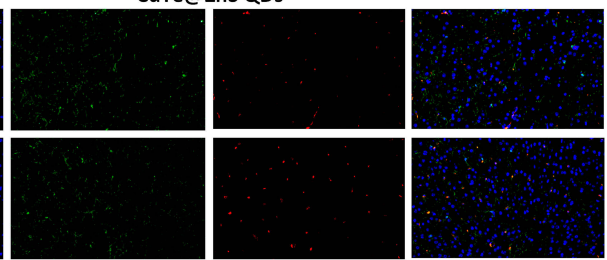

28 days

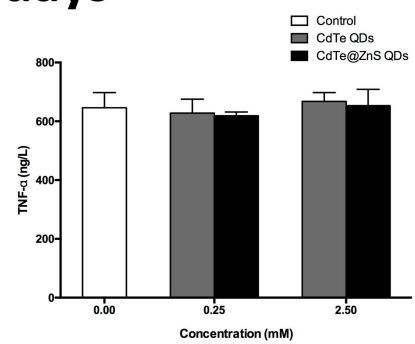

Figure 4 Cadmium-containing QD exposure caused microglial activation following with increased pro-inflammatory cytokines in the hippocampus. Representative immunofluorescence images presented the expressions of $\mathrm{Ibal}$ and $\mathrm{CDI} 6(\mathbf{A})$ or $\mathrm{IBI}$ and $\mathrm{CD} 206$ (B) in the hippocampus of mice injected with $0.25 \mathrm{mM} \times 0.1 \mathrm{~mL} / 20$ $\mathrm{g}$ BW and $2.5 \mathrm{mM} \times 0.1 \mathrm{~mL} / 20 \mathrm{~g}$ BW CdTe QDs and CdTe@ZnS QDs for $24 \mathrm{~h}$ and 28 days. The lba-I showed green by using a primary antibody with a FITC-linked secondary antibody, the CDI6 and CD206 showed red by using a primary antibody with a cy3-linked secondary antibody, and the nucleus showed blue by using DAPI. Magnification ( $\times 200$ ). (C) The effects of $0.25 \mathrm{mM} \times 0.1 \mathrm{~mL} / 20 \mathrm{~g}$ BW and $2.5 \mathrm{mM} \times 0.1 \mathrm{~mL} / 20 \mathrm{~g}$ BW CdTe QDs and CdTe@ZnS QD treatment for $24 \mathrm{~h}$ and 28 days on the levels of IL-I $B$ and TNF- $\alpha$ in hippocampus were determined by ELISA. Data are presented as the mean \pm SE of experiments performed independently three times. The oneway ANOVA following with the Tukey LSD post hoc test was used to determine statistical significance $(* * P<0.01$ vs the control). 

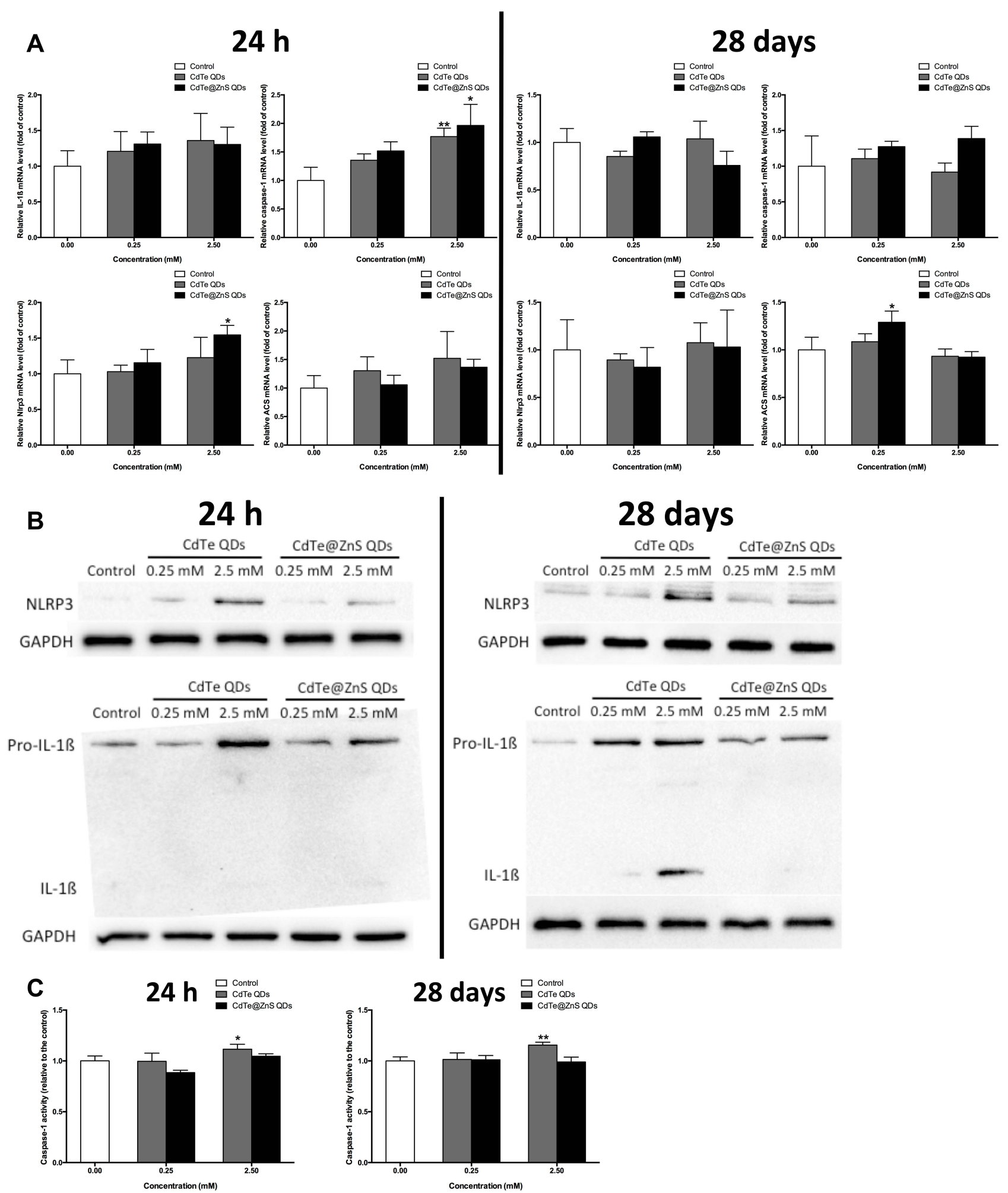

Figure 5 Cadmium-containing QD exposure activated the NLRP3 inflammasome in the hippocampus of mice. (A) The effects of $0.25 \mathrm{mM} \times 0.1 \mathrm{~mL} / 20 \mathrm{~g}$ BW and $2.5 \mathrm{mM} \times$ $0.1 \mathrm{~mL} / 20 \mathrm{~g}$ BW QD treatment for $24 \mathrm{~h}$ and 28 days on the expressions of IL-IB, caspase-I, NIrp3, and Asc mRNA in the hippocampus were measured by qRT-PCR analysis. (B) The effects of $0.25 \mathrm{mM} \times 0.1 \mathrm{~mL} / 20 \mathrm{~g} \mathrm{BW}$ and $2.5 \mathrm{mM} \times 0.1 \mathrm{~mL} / 20 \mathrm{~g} \mathrm{BW} \mathrm{QD}$ treatment for $24 \mathrm{~h}$ and 28 days on the protein expressions of intracellular pro-IL-IB, mature IL-I $B$ and NLRP3 in the hippocampus were measured by Western blotting analysis. (C) The effects of $0.25 \mathrm{mM} \times 0.1 \mathrm{~mL} / 20 \mathrm{~g} \mathrm{BW}$ and $2.5 \mathrm{mM} \times 0.1 \mathrm{~mL} / 20 \mathrm{~g} \mathrm{BW} \mathrm{QD}$ treatment for $24 \mathrm{~h}$ and 28 days on the caspase-I activity in hippocampus were determined by ELISA. Data are presented as the mean \pm SE of experiments performed independently three times. The one-way ANOVA following with the Tukey LSD post hoc test was used to determine statistical significance $(* P<0.05$, $* * P<0.0$ I vs the control). 
When BV2 cells were treated with cadmiumcontaining QDs for $12 \mathrm{~h}$, the cell viabilities all decreased (Figure 6A). After that, in BV2 cells with NLRP3 expression knocked down by RNAi technique, the upregulations in NLRP3 protein expression and IL-1 $\beta$ secretion caused by cadmium-containing QDs were both significantly inhibited (Figure 6B and $\mathrm{C}$ ).

\section{The ROS Excessive Generation Induced by Cadmium-Containing QDs Plays a Role in NLRP3 Inflammasome}

\section{Activation}

The results showed that $1 \mu \mathrm{M}$ CdTe QD and CdTe@ZnS QD exposure significantly increased ROS production in nematodes by detecting the fluorescence of reagent DCFHDA probes, particularly when exposed for $72 \mathrm{~h}$ (Figure 7A). Meanwhile, the significantly upregulated expressions of oxidative stress relevant genes, ie, sod-3 and ctl-2, by more than twofold, were observed in nematodes treated with CdTe QDs regardless of the treatment for $24 \mathrm{~h}$ or 72 $\mathrm{h}$, while only the expression of gene ctl-2 increased to over twofold in nematodes treated with CdTe@ZnS QDs for 24 $\mathrm{h}$ when compared to the control (Figure 7B and C).

The intracellular ROS in BV2 cells was also measured by using DCFH-DA probes but through flow cytometry. The mean fluorescence intensity (MFI) in BV2 cells exposed to $5 \mathrm{nM}$ cadmium-containing QDs were significantly stronger than the control, which indicated excessive ROS production after QD exposure (Figure 8A and B). The QDs-induced ROS generation could be effectively inhibited by pretreatment of a total ROS scavenger GSH (Figure 8C and D). Meanwhile, the GSH pretreatment also reversed the abnormal increases in NLRP3 protein expression and IL-1ß secretion in BV2 cells treated with cadmium-containing QDs (Figure 8E and F).

\section{Discussion}

The toxic effects of cadmium-containing QDs in the public and the environment are still receiving research
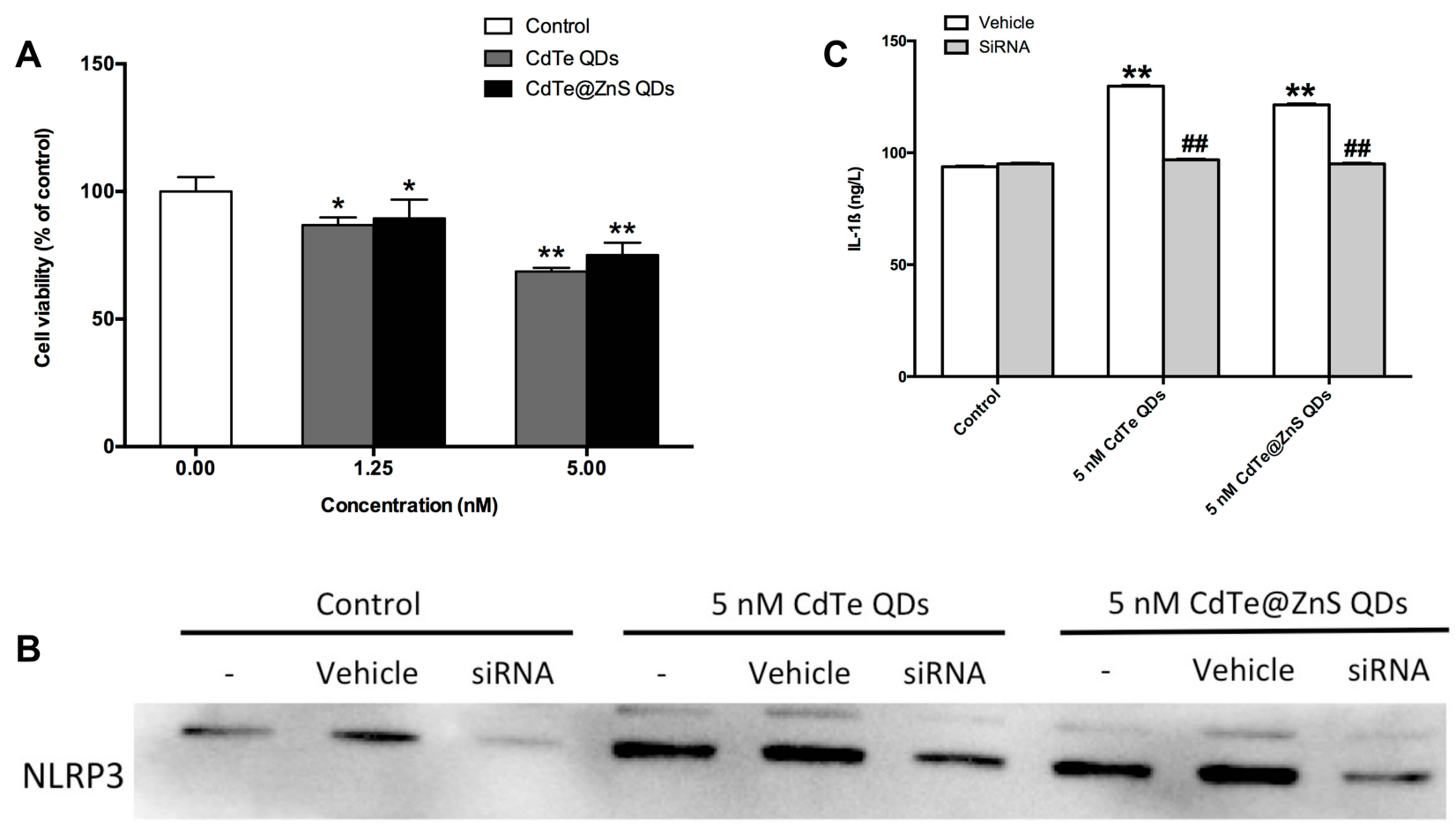

\section{GAPDH}

Figure 6 The NLRP3 inflammasome activation was involved in cadmium-containing QDs increasing IL-IB release in BV2 cells. (A) The effects of I.25 nM and 5 nM CdTe QDs and CdTe@ZnS QD treatment for $12 \mathrm{~h}$ in the cell viability of BV2 cells were measured by MTT assay. (B) The efficiency of siRNA against NLRP3 and its effects on the protein expression of NLRP3 in BV2 cells treated with $5 \mathrm{nM}$ CdTe QDs and CdTe@ZnS QDs for $12 \mathrm{~h}$ were measured by Western blotting analysis. (C) The effects of siRNA against NLRP3 on the levels of IL-I $B$ in the culture medium of BV2 cells treated with $5 \mathrm{nM}$ CdTe QDs and CdTe@ZnS QDs for I2 $\mathrm{h}$ were determined by ELISA. Data are presented as the mean \pm SE of experiments performed independently three times. The one-way ANOVA following with Tukey LSD post hoc test was used to determine statistical significance $(* P<0.05, * * P<0.01$ vs the control; \#P<0.01 vs the $5 \mathrm{nM} C d T e$ QDs and CdTe@ZnS QD treatment). 
A
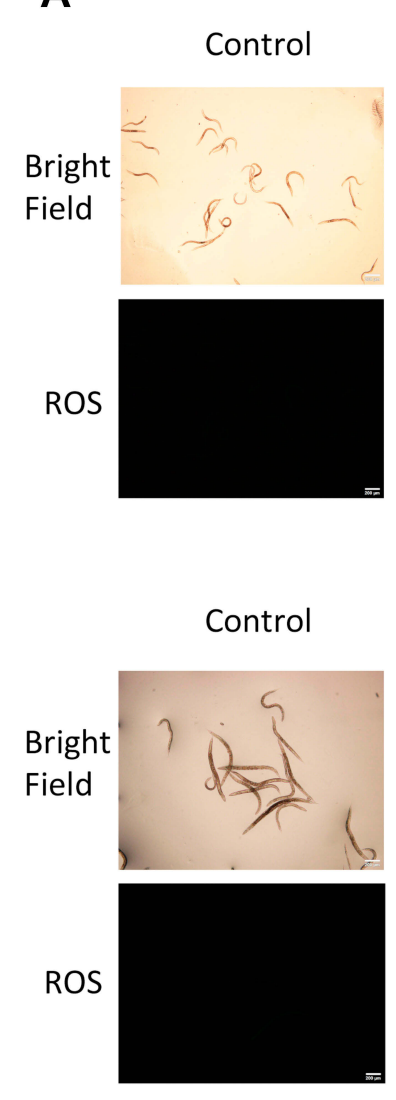

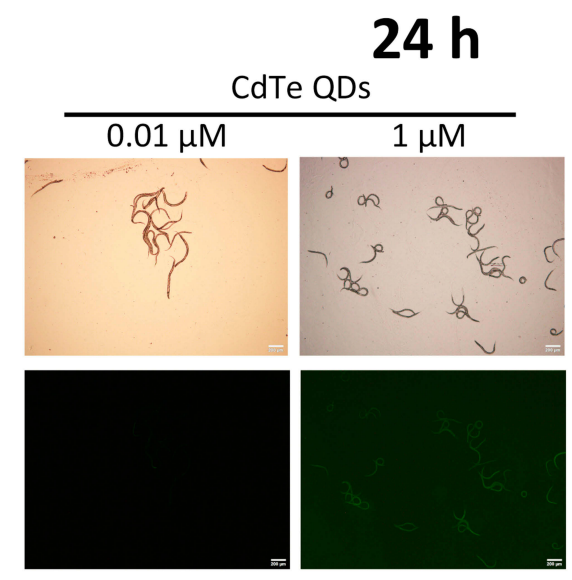

$72 \mathrm{~h}$
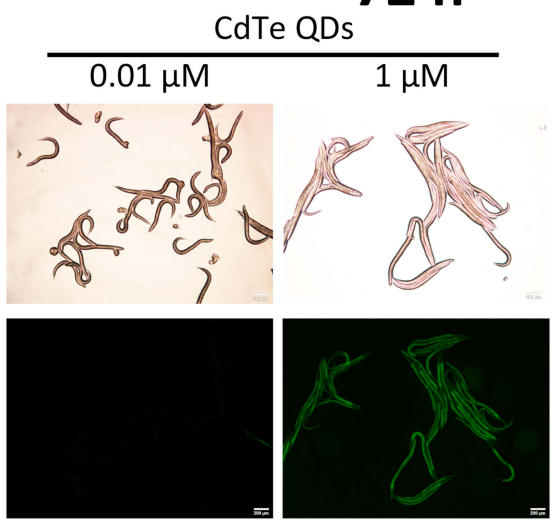

\section{CdTe@ZnS QDs}
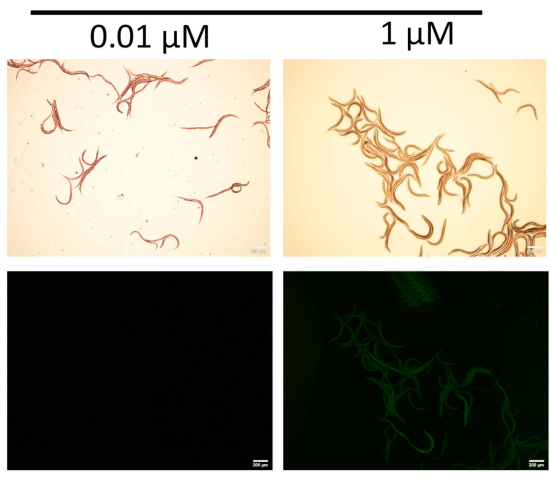

\section{CdTe@ZnS QDs}
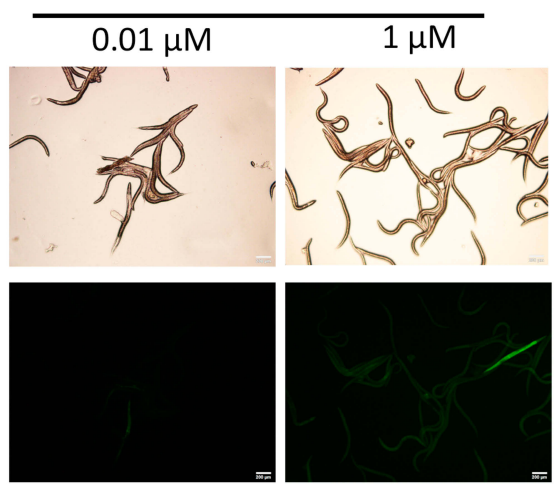

B

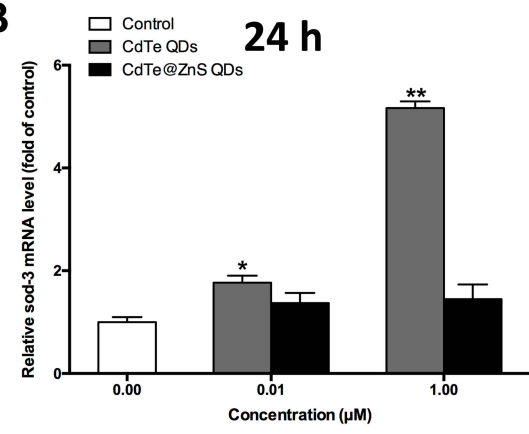

C

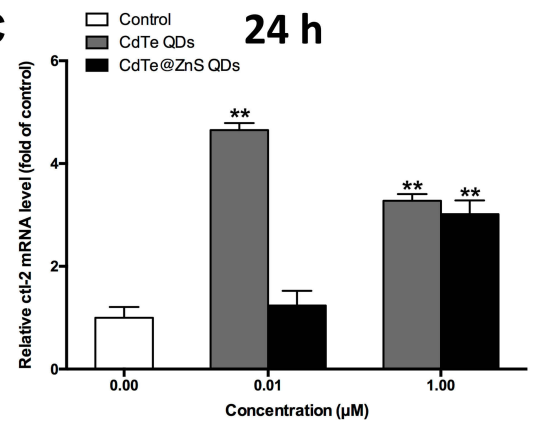

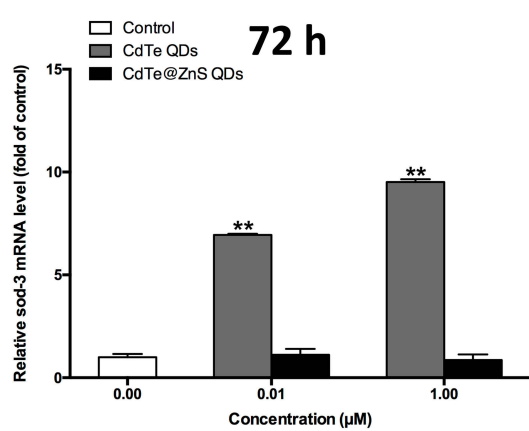

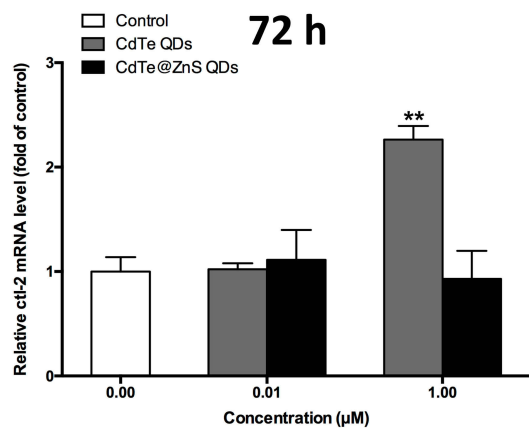

Figure 7 Cadmium-containing QD exposure caused oxidative stress in C. elegans. (A) The effects of $0.01 \mu M$ and I $\mu$ M CdTe and CdTe@ZnS QD treatment for 24 h and 72 $\mathrm{h}$ on the ROS generation in C. elegans were identified by a DCFH-DA probe. Magnification $(\times 100)$. The sod-3 (B) and ctl-2 (C) mRNA expressions in C. elegans treated with $0.01 \mu \mathrm{M}$ and I $\mu \mathrm{M}$ CdTe QDs and CdTe@ZnS QDs for $24 \mathrm{~h}$ and $72 \mathrm{~h}$ were measured by qRT-PCR analysis. Data are presented as the mean \pm SE of experiments performed independently three times. The one-way ANOVA following with the Tukey LSD post hoc test was used to determine statistical significance $(* P<0.05$, $* * P<0.0$ I vs the control). 
A

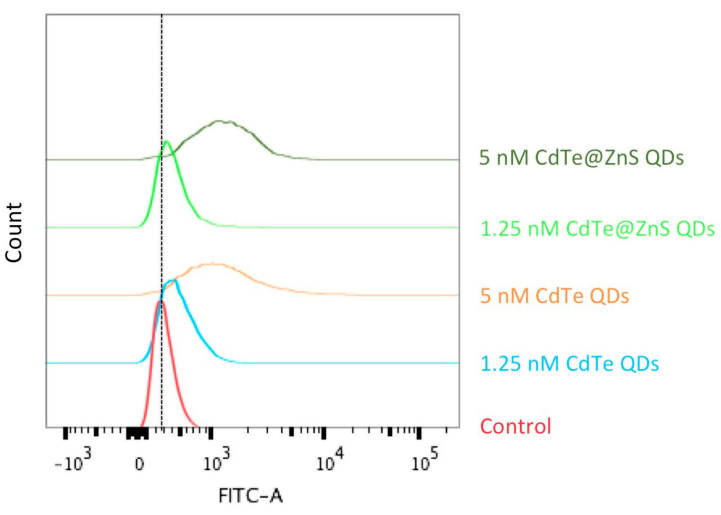

C

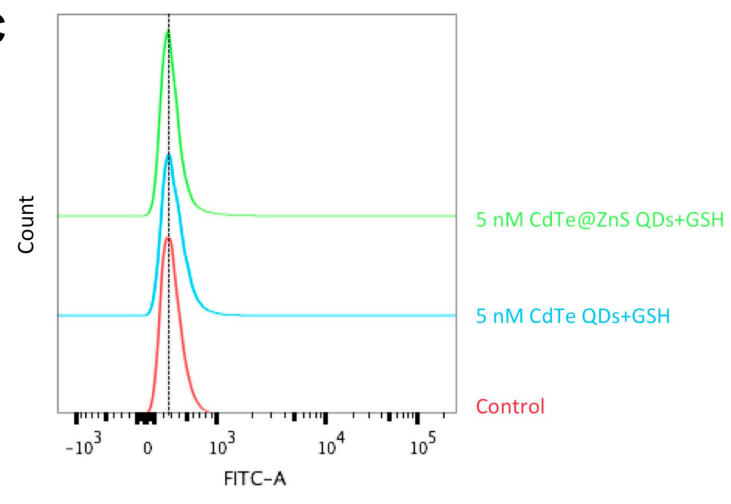

B

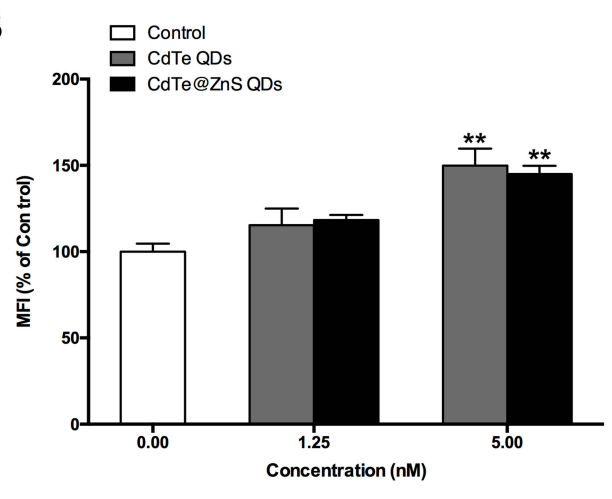

D

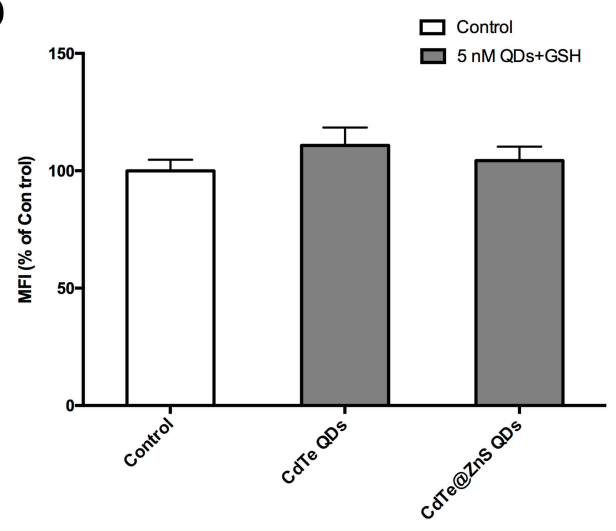

E

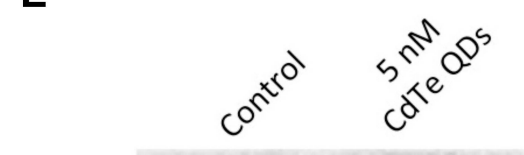

NLRP3

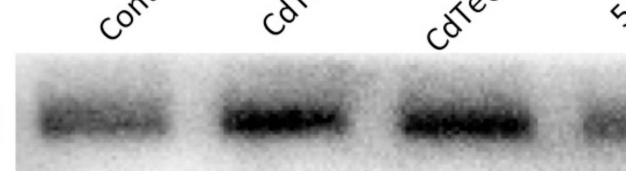

GAPDH
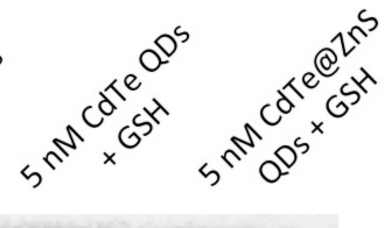

F

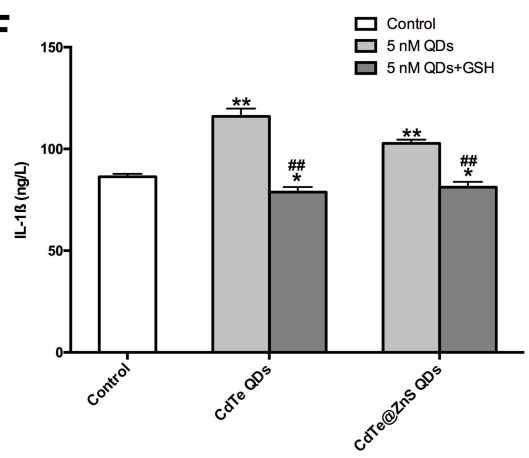

Figure 8 The role of ROS in cadmium-containing QDs inducing NLRP3 inflammasome activation and IL-IB release in BV2 cells. (A, B) The effects of I.25 nM and 5 nM CdTe QDs and CdTe@ZnS QD treatment for 12 h in BV2 cells on the intracellular ROS generation were identified by using flow cytometry with a DCFH-DA probe. (C, D) The effects of a total ROS scavenger GSH pretreatment on the intracellular ROS generation in BV2 cells treated with $5 \mathrm{nM}$ CdTe QDs and CdTe@ZnS QDs for I2 h were identified by using flow cytometry with a DCFH-DA probe. (E) The effects of GSH on protein NLRP3 expression in BV2 cells treated with 5 nM CdTe QDs and CdTe@ZnS QDs for $12 \mathrm{~h}$ were measured by Western blotting analysis. (F) The effects of GSH on the active IL-I $\mathrm{B}$ level in the culture medium of BV2 cells treated with $5 \mathrm{nM}$ CdTe QDs and CdTe@ZnS QDs for $12 \mathrm{~h}$ were determined by ELISA. Data are presented as the mean \pm SE of experiments performed independently three times. The one-way ANOVA, followed by Tukey LSD post hoc test, was used to determine statistical significance $(* P<0.05$, $* * P<0.01$ vs the control; \#\#P0.0I vs the $5 \mathrm{nM}$ CdTe QDs and CdTe@ZnS QD treatment)

attention because of their growing application. Coating CdTe QDs with a $\mathrm{ZnS}$ shell is a common way to prevent cadmium releasing from CdTe QDs in order to control their toxicity, but the protective role of $\mathrm{ZnS}$ shell is not assured right now. In this study, the highly water-soluble CdTe QDs and CdTe@ZnS QDs are valuable in vivo imaging probes and could translocate into the CNS. ${ }^{30}$ Thus, it is important to assess the neurotoxicity of these two kinds of cadmiumcontaining QDs in living bodies. 
Herein, C. elegans was used because it possesses organs that represent most essential biological systems of a living organism, including the nervous system and the immune system, as well as having the advantages of large brood size, short life cycle, and inexpensive maintenance. ${ }^{31}$ The lifespans were decreased in nematodes treated with cadmium-containing QDs in a dose- and time-dependent manner, which indicated immunity injury caused by QDs. Since genes of lys-1, spp-1, and dod-6 are all involved in immune responses to foreign materials in C. elegans, ${ }^{32,33}$ the upregulations in the expression of these immune genes after CdTe QD exposure suggested the immune responses to QDs in living bodies. Furthermore, C. elegans nematodes have an integrated innate immune system but a deficient adaptive immunity system, and the Daf-2/Daf-16 pathway and p38 MAPK pathway are two main pathways involved in host defense and inflammatory functions. ${ }^{34,35}$ The findings showed that CdTe QD exposure increased the expression levels of key genes in $\mathrm{p} 38$ and Daf-2/Daf-16 pathways, which demonstrated the role of CdTe QDs in the positive modulation of immunity in living animals. However, the expression levels of most tested immune genes did not change in nematodes treated with CdTe@ZnS QDs.

Nervous system injuries caused by cadmium-containing QDs in nematodes can be evaluated by using quantitative behavioral measurements as sensitive endpoints. ${ }^{36,37}$ Two kinds of cadmium-containing QD treatments, especially CdTe QDs, could change the locomotion behaviors in nematodes in an adverse way. When the administration concentration and time are the same, the damage to lifespan, immunity, and behavior of nematodes caused by CdTe QDs was far more severe than those caused byCdTe@ZnS QDs.

The findings in C. elegans provide an explicit conclusion that cadmium-containing QDs caused immune responses and nervous system damages in living animals, and the $\mathrm{ZnS}$ shell could effectively alleviate the neurotoxicity of CdTe QDs. After that, experimental mice were used to assess the pro-inflammatory ability and neurotoxicity of cadmium-containing QDs in living mammals. Apart from a slight systemic inflammation that was evidenced by the increased levels of pro-inflammatory cytokines and immune cells in the circular system, CdTe QDs and CdTe@ZnS QDs did not cause severe damage in the general health of mice at doses used for in vivo fluorescent imaging. Importantly, cadmium-containing QD exposure caused immune reactions in the hippocampus of mice, which were indicated by the neutrophil infiltration in the hippocampus and upregulated protein PECAM-1/CD31 expression that was considered as a crucial molecule in neuroinflammation. ${ }^{38,39}$

In this study, QD-induced microglial activation and inflammatory reactions to QDs in the hippocampus occur quickly (24 $\mathrm{h}$ after QD exposure), and continue to 28 days, which is similar to some other kinds of nanoparticles, which were reported to activate microglia and result in neuroinflammation. ${ }^{40-42}$ Furthermore, two phenotypes of activated microglia, ie, M1 (pro-inflammatory) and M2 (anti-inflammatory and repairlike), were both observed in the hippocampus, so it seems that the inflammation promoted by cadmium-containing QDs in the hippocampus is a little complex.

The neuroinflammatory responses to cadmiumcontaining QDs were also confirmed by the increased proinflammatory cytokine IL- $1 ß$ level in the hippocampus treated with CdTe QDs. The transcriptome analysis provided a hint that the activation of the NOD-like receptor pyrin domain containing 3 (NLRP3) inflammasome might be involved in cadmium-containing QDs causing IL-1ßmediated inflammation in the hippocampus. The results suggested that cadmium-containing QDs enhanced not only the NLRP3 protein expression but also caspase-1 activity, a key component of the multiprotein complex NLRP3 inflammasome, in the hippocampus. ${ }^{43}$ More importantly, CdTe QDs caused more serious IL-1ß-mediated inflammation in the hippocampus than CdTe@ZnS QDs, which might be related to the fact that the $\mathrm{ZnS}$ coating prevented CdTe QDs from significantly activating the NLRP3 inflammasome.

Owing to the important role of microglia mediating inflammation in the CNS, a microglial cell line (BV2 cells) was used to evaluate the molecular mechanisms of neuroinflammatory responses to QDs in vitro. Unsurprisingly, cadmium-containing QDs decreased the cell viability of BV2 cells. In BV2 cells with NLRP3 knocked down, cadmiumcontaining QD exposure failed to increase the IL-1ß secretion, which indicated the important mediation of NLRP3 inflammasome activation in IL-1ß release caused by QDs.

Recently, among the factors that are evaluated by researchers to activate NLRP3 inflammasome, excessive ROS generation is a common consequence of QDs. ${ }^{44}{ }^{47}$ In C. elegans treated with cadmium-containing QDs, the increased production of ROS in nematode bodies was observed, which is similar to previous studies suggesting nanoscale materials induced oxidative stress in C. elegans. ${ }^{23,48}$ Meanwhile, the enhanced expression of antioxidant enzyme genes sod-3 and ctl-2 in C. elegans treated with CdTe QDs also indicated that CdTe QDs could induce oxidative stress resistance in nematodes. ${ }^{49}$ 
The increased level of intracellular ROS caused by cadmium-containing QDs could be inhibited by a ROS scavenger GSH in BV2 cells. Pretreatment with GSH also could effectively reduce the increases in NLRP3 protein expression and IL-1ß release caused by cadmiumcontaining QDs, which demonstrated that excessive ROS generation induced by QDs was the direct activator of the NLRP3 inflammasome, and then resulted in IL-1ß release in BV2 cells.

When comparing the neuroinflammatory responses to these two kinds of cadmium-containing QDs, the CdTe@ZnS QD exposure caused milder damage than CdTe QDs in terms of immune reactions and neurotoxic effects in C. elegans as well as microglial activation and IL-1ß-mediated inflammation in the hippocampus, which indicated the protective role of the $\mathrm{ZnS}$ shell. However, CdTe QDs and CdTe@ZnS QDs were both capable of causing excessive ROS production and activating the NLRP3 inflammasome in different degrees, which suggested that the $\mathrm{ZnS}$ shell still failed to prevent some adverse effects caused by CdTe QDs at a molecular level. Fortunately, inhibiting oxidative stress induced by QDs would be an effective and efficient way to control the promoting-inflammatory effects of QDs.

\section{Conclusion}

In this study, we firstly observed the immune responses to CdTe QDs and CdTe@ZnS QDs and their neurotoxicity in a valuable in vivo biological model $C$. elegans. On this basis, these two kinds of cadmium-containing QDs causing microglial activation followed by mainly IL-1ß-mediated inflammation were observed in the hippocampus of mice treated with QDs. According to the hint of cadmiumcontaining QDs being an activator of NLRP3 inflammasome from the transcriptome analysis, we found that QDs exposure could activate NLRP 3 inflammasome by causing excessive ROS generation and resulted in IL-1ß-mediated inflammation in microglia. Generally, CdTe@ZnS QDs caused milder neuroinflammatory reactions than CdTe QDs in vivo and in vitro, which indicated the partially protective role of the $\mathrm{ZnS}$ shell. However, the inhibitions of NLRP3 inflammasome activation and ROS generation basically reduced the increased IL- $1 \beta$ release caused by cadmiumcontaining QDs. It seems that the way of inhibiting molecular targets of QDs is effective and efficient to control their toxicity. This study emphasizes the necessity to assess QDs through a mechanism-based toxicological approach to control their toxicity. Further studies should focus on the influence of various chemical compositions on the toxicity of QDs.

\section{Acknowledgments}

This work was supported by National Natural Science Foundation of China (grant numbers 21876026, 31671034, 81473003, 81502783), Provincial Natural Science Funds of Jiangsu (grant number BK20180371), Fundamental Research Funds for the Central Universities (grant number 2242019K40220, 2242020K40192) and Supporting Program of Southeast University Zhishan Young Scholar.

\section{Disclosure}

The authors report no conflicts of interest in this work.

\section{References}

1. Hauck TS, Anderson RE, Fischer HC, et al. In vivo quantum-dot toxicity assessment. Small. 2010;6(1):138-144. doi:10.1002/ smll.200900626

2. Medintz IL, Uyeda HT, Goldman ER, et al. Quantum dot bioconjugates for imaging, labelling and sensing. Nat Mater. 2005;4 (6):435-446. doi:10.1038/nmat1390

3. Lin CC, Han H-V, Chen H-C, et al. Highly efficient multiple-layer CdS quantum dot sensitized III-V solar cells. J Nanosci Nanotechnol. 2014;14:1051-1063. doi:10.1166/jnn.2014.9125

4. Chen N, He Y, Su Y, et al. The cytotoxicity of cadmium-based quantum dots. Biomaterials. 2012;33(5):1238-1244. doi:10.1016/j. biomaterials.2011.10.070

5. Wang J, Liu R, Liu B, et al. Cadmium-containing quantum dots: current perspectives on their application as nanomedicine and toxicity concerns. Mini Rev Med Chem. 2016;16(11):905-916. doi:10.2174/ 1389557516666160211121247

6. Wu T, Zhang T, Chen Y, et al. Research advances on potential neurotoxicity of quantum dots. J Appl Toxicol. 2016b;36(3):345-351. doi:10.1002/jat.3229

7. $\mathrm{Wu} \mathrm{T}, \mathrm{He} \mathrm{K}$, Ang $\mathrm{S}$, et al. Impairments of spatial learning and memory following intrahippocampal injection in rats of 3-mercaptopropionic acid-modified CdTe quantum dots and molecular mechanisms. Int J Nanomedicine. 2016a;19:5-12. doi:10.2147/ IJN.S104985

8. Wu T, Liang X, He K, et al. Transcriptome analysis of different sizes of 3-mercaptopropionic acid-modified cadmium telluride quantum dot-induced toxic effects reveals immune response in rat hippocampus. J Appl Toxicol. 2018a;38(9):1177-1194. doi:10.1002/jat.3629

9. Manshian BB, Soenen SJ, Al-Ali A, et al. Cell type-dependent changes in $\mathrm{CdSe} / \mathrm{ZnS}$ quantum dot uptake and toxic endpoints. Toxicol Sci. 2015;144(2):246-258. doi:10.1093/toxsci/kfv002

10. Tang S, Allagadda V, Chibli H, et al. Comparison of cytotoxicity and expression of metal regulatory genes in zebrafish (Danio rerio) liver cells exposed to cadmium sulfate, zinc sulfate and quantum dots. Metallomics. 2013;5(10):1411-1422. doi:10.1039/c3mt20234h

11. Saikia D, Chakravarty S, Sarma NS, et al. Aqueous synthesis of highly stable $\mathrm{CdTe} / \mathrm{ZnS}$ Core/Shell quantum dots for bioimaging. Luminescence. 2017;32(3):401-408. doi:10.1002/bio.3193

12. Wu T, He K, Liang X, et al. The glycolytic shift was involved in $\mathrm{CdTe} / \mathrm{ZnS}$ quantum dots inducing microglial activation mediated through the mTOR signaling pathway. J Appl Toxicol. 2019a. doi:10.1002/jat.3912 
13. Wu TS, Liang X, He K, et al. MPA-modified CdTe quantum dots increased interleukin-1beta secretion through MyD88-dependent Toll-like receptor pathway and NLRP3 inflammasome activation in microglia. Toxicol in Vitro. 2018b;52:41-51. doi:10.1016/j. tiv.2018.05.014

14. Avila D, Helmcke K, Aschner M, et al. The Caenorhabiditis elegans model as a reliable tool in neurotoxicology. Hum Exp Toxicol. 2012;31(3):236-243. doi:10.1177/0960327110392084

15. Kwon G, Lee J, Lim Y-H, et al. Dairy Propionibacterium extends the mean lifespan of Caenorhabditis elegans via activation of the innate immune system. Sci Rep. 2016;6(1):31713. doi:10.1038/srep31713

16. Wani KA, et al. Nervous system control of intestinal host defense in C. elegans. Curr Opin Neurobiol. 2019;62:1-9.

17. He K, Liang X, Wei T, et al. DNA damage in BV-2 cells: an important supplement to the neurotoxicity of CdTe quantum dots. J Appl Toxicol. 2019;39(3):525-539. doi:10.1002/jat.3745

18. Liu J, Zhang Y, Ge C, et al. Preparation and characterization of highly luminescent water-soluble CdTe quantum dots as optical temperature probes. J Nanosci Nanotechnol. 2010;10(11):7578-7582. doi:10.1166/jnn.2010.2851

19. Wu T, Liang X, He K, et al. The role of NLRP3 inflammasome activation in the neuroinflammatory responses to $\mathrm{Ag} 2 \mathrm{Se}$ quantum dots in microglia. Nanoscale. 2019b;11(43):20820-20836. doi:10.1039/C9NR06778G

20. Lewis JA, Fleming JT. Basic culture methods. Methods Cell Biol. 1995;48(48):3-29.

21. Zhuang ZH, Li M, Liu H, et al. Function of RSKS-1-AAK-2-DAF-16 signaling cascade in enhancing toxicity of multi-walled carbon nanotubes can be suppressed by mir-259 activation in Caenorhabditis elegans. Sci Rep. 2016;6.

22. Scharf A, Gührs K-H, von Mikecz A, et al. Anti-amyloid compounds protect from silica nanoparticle-induced neurotoxicity in the nematode C. elegans. Nanotoxicology. 2016;10:426-435. doi:10.3109/ 17435390.2015 .1073399

23. Wu T, He K, Zhan Q, et al. MPA-capped CdTe quantum dots exposure causes neurotoxic effects in nematode Caenorhabditis elegans by affecting the transporters and receptors of glutamate, serotonin and dopamine at the genetic level, or by increasing ROS, or both. Nanoscale. 2015;7(48):20460-20473. doi:10.1039/C5NR05914C

24. Bujnakova Z, Baláž M, Dutková E, et al. Mechanochemical approach for the capping of mixed core $\mathrm{CdS} / \mathrm{ZnS}$ nanocrystals: elimination of cadmium toxicity. J Colloid Interface Sci. 2017;486:97-111. doi:10.1016/j.jcis.2016.09.033

25. Ermolaeva MA, Schumacher B. Insights from the worm: the C. elegans model for innate immunity. Semin Immunol. 2014;26 (4):303-309. doi:10.1016/j.smim.2014.04.005

26. Park H-EH, Jung Y, Lee S-JV, et al. Survival assays using Caenorhabditis elegans. Mol Cells. 2017;40(2):90-99. doi:10.14348/ molcells.2017.0017

27. Piechulek A, von Mikecz A. Life span-resolved nanotoxicology enables identification of age-associated neuromuscular vulnerabilities in the nematode Caenorhabditis elegans. Environ Pollut. 2018;233:1095-1103. doi:10.1016/j.envpol.2017.10.012

28. Soares MV, Charão MF, Jacques MT, et al. Airborne toluene exposure causes germline apoptosis and neuronal damage that promotes neurobehavioural changes in Caenorhabditis elegans. Environ Pollut. 2019;113406.

29. Thakkar R, Wang R, Wang J, et al. 17ß-estradiol regulates microglia activation and polarization in the hippocampus following global cerebral ischemia. Oxid Med Cell Longev. 2018;2018:4248526. doi:10.1155/2018/4248526

30. Zhao Y, Zhang Y, Qin G, et al. In vivo biodistribution and behavior of CdTe/ZnS quantum dots. Int J Nanomedicine. 2017;12:1927-1939. doi:10.2147/IJN.S121075

31. Leung MC, Williams PL, Benedetto A, et al. Caenorhabditis elegans: an emerging model in biomedical and environmental toxicology. Toxicol Sci. 2008;106:5-28.
32. Kimura $\mathrm{T}$, Takanami $\mathrm{T}$, Sakashita $\mathrm{T}$, et al. Innate immune genes including a mucin-like gene, mul-1, induced by ionizing radiation in caenorhabditis elegans. Radiat Res. 2012;178(4):313-320. doi:10.1667/RR2989.1

33. Liu J, Hafting J, Critchley AT, et al. Components of the cultivated red seaweed chondrus crispus enhance the immune response of caenorhabditis elegans to pseudomonas aeruginosa through the pmk-1, daf-2/daf-16, and skn-1 pathways. Appl Environ Microbiol. 2013;79 (23):7343-7350. doi:10.1128/AEM.01927-13

34. Kwon G, Lee J, Koh J-H, et al. Lifespan extension of caenorhabditis elegans by butyricicoccus pullicaecorum and megasphaera elsdenii with probiotic potential. Curr Microbiol. 2018;75(5):557-564. doi:10.1007/s00284-017-1416-6

35. Tissenbaum HA. DAF-16: FOXO in the context of C. elegans. Curr Top Dev Biol. 2018;127:1-21.

36. Handy RD, Cornelis G, Fernandes T, et al. Ecotoxicity test methods for engineered nanomaterials: practical experiences and recommendations from the bench. Environ Toxicol Chem. 2012;31(1):15-31. doi:10.1002/etc. 706

37. Meyer D, Williams PL. Toxicity testing of neurotoxic pesticides in Caenorhabditis elegans. J Toxicol Environ Health B Crit Rev. 2014;17:284-306. doi:10.1080/10937404.2014.933722

38. Almutairi MM, Gong C, Xu YG, et al. Factors controlling permeability of the blood-brain barrier. Cell Mol Life Sci. 2016;73:57-77. doi:10.1007/s00018-015-2050-8

39. Aroca F, Renaud W, Bartoli C, et al. Expression of PECAM-1/CD31 isoforms in human brain gliomas. J Neurooncol. 1999;43(1):19-25. doi:10.1023/A:1006233816724

40. Nemeth CL, Drummond GT, Mishra MK, et al. Uptake of dendrimer-drug by different cell types in the hippocampus after hypoxic-ischemic insult in neonatal mice: effects of injury, microglial activation and hypothermia. Nanomedicine. 2017;13:2359-2369. doi:10.1016/j.nano.2017.06.014

41. Patchin ES, Anderson DS, Silva RM, et al. Size-dependent deposition, translocation, and microglial activation of inhaled silver nanoparticles in the rodent nose and brain. Environ Health Perspect. 2016;124(12):1870-1875. doi:10.1289/EHP234

42. Rihane N, Nury T, M'rad I, et al. Microglial cells (BV-2) internalize titanium dioxide ( $\mathrm{TiO} 2$ ) nanoparticles: toxicity and cellular responses. Environ Sci Pollut Res Int. 2016;23(10):9690-9699. doi:10.1007/s11356-016-6190-7

43. $\mathrm{Lu} \mathrm{Y}, \mathrm{Xu} \mathrm{S}$, Chen $\mathrm{H}$, et al. CdSe/ZnS quantum dots induce hepatocyte pyroptosis and liver inflammation via NLRP3 inflammasome activation. Biomaterials. 2016;90:27-39. doi:10.1016/j. biomaterials.2016.03.003

44. Dagenais M, Skeldon A, Saleh M, et al. The inflammasome: in memory of Dr. Jurg Tschopp. Cell Death Differ. 2012;19:5-12. doi:10.1038/cdd.2011.159

45. Schroder K, Tschopp J. The inflammasomes. Cell. 2010;140 (6):821-832. doi:10.1016/j.cell.2010.01.040

46. Shirasuna K, Karasawa T, Takahashi M, et al. Exogenous nanoparticles and endogenous crystalline molecules as danger signals for the NLRP3 inflammasomes. $J$ Cell Physiol. 2019;234 (5):5436-5450. doi: $10.1002 /$ jep. 27475

47. Silva AL, Peres C, Conniot J, et al. Nanoparticle impact on innate immune cell pattern-recognition receptors and inflammasomes activation. Semin Immunol. 2017;34:3-24. doi:10.1016/j.smim. 2017.09.003

48. Cao X, Wang X, Chen H, et al. Neurotoxicity of nonylphenol exposure on Caenorhabditis elegans induced by reactive oxidative species and disturbance synthesis of serotonin. Environ Pollut. 2019;244:947-957. doi:10.1016/j.envpol.2018.09.140

49. Zhao Y, Wang X, Wu Q, et al. Quantum dots exposure alters both development and function of D-type GABAergic motor neurons in nematode Caenorhabditis elegans. Toxicol Res (Camb). 2015;4 (2):399-408. doi:10.1039/C4TX00207E 


\section{Publish your work in this journal}

The International Journal of Nanomedicine is an international, peerreviewed journal focusing on the application of nanotechnology in diagnostics, therapeutics, and drug delivery systems throughout the biomedical field. This journal is indexed on PubMed Central, MedLine, CAS, SciSearch ${ }^{\circledR}$, Current Contents ${ }^{\circledR} /$ Clinical Medicine,
Journal Citation Reports/Science Edition, EMBase, Scopus and the Elsevier Bibliographic databases. The manuscript management system is completely online and includes a very quick and fair peer-review system, which is all easy to use. Visit http://www.dovepress.com/ testimonials.php to read real quotes from published authors. 